NASA Technical Memorandum 102065

AIAA-89-2492

\title{
The NASA Low Thrust Propulsion Program
}

James R. Stone and Gary L. Bennett

NASA Headquarters

Office of Aeronautics and Space Technology

Washington, D.C.

Prepared for the

25th Joint Propulsion Conference

cosponsored by the AIAA, ASME, SAE, and ASEE

Monterey, California, July 10-12, 1989 


\title{
THE NASA LOW THRUST PROPULSION PROGRAM
}

\author{
James R. Stone and Gary L. Bennett \\ NASA Headquarters \\ Office of Aeronautics and Space Technology \\ Washington, DC 20546
}

\begin{abstract}
SUMMARY
The NASA OAST Propulsion, Power, and Energy Division supports a low thrust propulsion program aimed at providing high performance options to a broad range of near-term and far-term missions and vehicles. Low thrust propulsion has a major impact on the mission performance of essentially all spacecraft and vehicles. On-orbit lifetimes, payloads, and trip times are significantly impacted by low thrust propulsion performance and integration features for Earth-toorbit (ETO) vehicles, Earth-orbit and planetary spacecraft, and large platforms in Earth orbit. Major emphases of the program are on low thrust chemical, both storables and hydrogen/oxygen; low-power (auxiliary) electric arcjets and resistojets; and high-power (primary) electric propulsion, including ion, magnetoplasmadynamic (MPD), and electrodeless concepts. This paper will present the major recent accomplishments of the program and discuss their impacts.
\end{abstract}

\section{INTRODUCTION}

The identification and development of new propulsion systems is fundamental to the continued effectiveness of NASA. Accordingly, NASA continues to maintain a technology program which spans focused development on Earth-to-orbit (ETO) and chemical transfer propulsion, basic propulsion research and technology ( $R \& T)$, and advanced propulsion concepts (ref. 1). Essentially all spacecraft and vehicles incorporate low thrust propulsion systems which contribute a significant fraction of the vehicle/spacecraft mass, and the cost of delivering mass to low Earth orbit (LEO) is a major fraction of the cost of any mission. For example, on the Galileo mission, propellant accounts for 43 percent of the total mass and for the more challenging (larger velocity increment) comet rendezvous asteroid flyby (CRAF) mission, the propellant fraction is 76 percent (ref. 2). The objective of the low-thrust primary and auxilary propulsion program, which is the focus of this paper, is to provide the basis for increased performance and operational life of small thruster systems by developing fundamental understanding in the areas of high-temperature materials, fluid physics, electrical and magnetic fields, and ion physics.

The emphasis of this program is on high-risk, high-payoff technologies such as chemical thrusters, arcjets, resistojets, ion engines, and magnetoplasmadynamic (MPD) thrusters. The work is principally being carried out through two NASA centers: the Jet Propulsion Laboratory (JPL) and Lewis Research Center (NASA Lewis). Both centers are working on a complementary program to advance the technology for low-thrust propulsion systems for a broad range of future space platforms, spacecraft, launch, and orbit transfer vehicles. JPL has been focusing principally on (1) improving ion engine life; (2) simplifying multiengine system architecture; and (3) developing the technology necessary to build and test an MPD thruster capable of steady-state operation at power levels and several megawatts. NASA Lewis has been focusing 
principally on (1) improving chemical systems; (2) research on high-performance arcjets; and (3) basic physics and scalability of inert-gas ion thrusters and high-power MPD thrusters. There is a close interchange between JPL and NASA Lewis, and the two programs both complement and supplement each other.

This paper focuses primarily on progress beyond that reported at the 24 th Joint Propulsion Conference (ref. 3), but some references to earlier work are included for clarity and continuity.

\section{CHEMICAL}

Low thrust chemical propulsion finds application to a broad class of vehicles including ETO vehicles, Earth-orbital and planetary spacecraft and large platforins, including Space Station Freedom, in Earth orbit. On ETO vehicles storable propellants are currently used for on-orbit propulsion, but future systems may take advantage of using residual primary propellants (hydrogen or hydrocarbons and oxygen) for these functions. Advantages may accrue from both the use of scavenged residuals and from the increase in specific impulse $\left(I_{s p}\right)$. New architectures including propellant resupply create emphasis on extended life as well as increased performance. A high-temperature thruster effort is being conducted using advanced materials and diagnostic techniques and is aimed at increased performance and life with state-of-the-art and advanced storable propellants. Both storable (monopropellant hydrazine) and gaseous hydrogen/oxygen ( $H / O)$ systems have been investigated for Freedom.

Due in part to problems with Galileo's $10-\mathrm{N}$ thrusters, interest has been heightened in understanding the fundamentals of small rockets. Support for small rocket fundamental research is provided by the Advanced Transportation Propulsion and Low Thrust Propulsion programs. This effort, which was initiated under the Low Thrust Propulsion program, is discussed briefly herein.

\section{Storable Propellants}

Low-thrust, storable, monopropellant and bipropellant propulsion is widely used on a variety of spacecraft, ranging from small satellites to the space shuttle.

Bipropellant. - Storable bipropellants are used for many Earth-orbital and planetary spacecraft. A major accomplishment at NASA Lewis and Aerojet this past year has been the achievement of an extraordinary increase $(\sim 900 \mathrm{~K})$ in chamber operating temperature for a $22-\mathrm{N}$ advanced storable rocket using nitrogen tetroxide $\left(\mathrm{N}_{2} \mathrm{O}_{4}\right.$ or NTO) and monomethyl hydrazine (MMH) (ref. 4). The thruster, shown operating in figure 1, consists of iridium-coated rhenium fabricated by a chemical vapor deposition (CVD) process wherein the iridium coating is first deposited on an expendable mandrel of molybdenum and then the thicker rhenium layer deposited on top of it (ref. 5). The rhenium offers the desired high-temperature strength while iridium provides the needed oxidation resistance. Because of the high melting point of iridium temperatures approaching $2700 \mathrm{~K}$ are possible. This can also translate into a greater than tenfold increase in the operating life. This technology clearly overcomes the problems that existing thrusters have presented to NASA and other spacecraft users. 
Aerojet first tested two iridium-coated rhenium thrust chambers with $8: 1$ expansion ratio, and over $15 \mathrm{hr}$ of operation was demonstrated at temperatures from 2250 to $2530 \mathrm{~K}$ without fallure or any evidence of corrosive attack or measurable change in throat dimensions. Similar results were recently demonstrated on a 22-N thruster with 150:1 expansion ratio fabricated from the same materials by the same technique (ref. 6). The significance of this can be seen in figure 2 which compares the state-of-the art (SOA) disilicide-coated niobium alloy chamber with the Ir/Re chamber. Not only does the Ir/Re chamber offer extended lifetimes but it offers higher $I_{\text {sp. }}$. Because of this performance advance, NASA initially selected this technology for the Mariner Mark 11 comet rendezvous asteroid flyby (CRAF) mission. The reduced propellant mass $(\sim 600 \mathrm{~kg})$ enabled the addition of three experiments to the spacecraft. To assure the readiness of this technology for the mission, the NASA Office of Space Science and Applications supported Aerojet, under the management of the $\mathrm{JPL}$, for fabrication and test of a 440-N iridium-coated rhenium thruster, with the CVD processing performed by Ultramet. A 4-hr test indicated feasibility of the desired performance and life (ref. 7). While some spalling of the iridium has occurred because of contaminants that affected the iridium deposition both engines are serviceable and await additional testing. NASA Lewis is continuing to work with Ultramet to improve the fabrication process. A delay in the CRAF mission has recently occurred, resulting in less challenging propulsion requirements and a decision to use a propulsion system provided by NASA's European partner in this mission.

Monopropellant. - Although multipropellant resistojets and hydrogen/ oxygen were baselined for Freedom propulsion, the technology of monopropellant hydrazine propulsion was advanced to provide a design option which might have lower development cost (although operating costs would be higher due to the requirement for propellant resupply). A life test of a 22-N thruster was conducted under a cooperation program between the Rocket Research Co. and NASA Lewis. The total impulse capability of $4.8 \times 10^{6} \mathrm{~N}-\mathrm{s}$ demonstrated is the greatest reported for small hydrazine rockets (ref. 8 ).

\section{Hydrogen/0xygen}

Space Station Freedom. - Based on earlier studies manned space stations, two propulsion systems were investigated for different functions (refs. 9 to 11). As discussed elsewhere in this paper, low power multipropellant resistojets were selected for drag make-up. For the high-thrust ( 110 to $220 \mathrm{~N})$ function, gaseous H/O thrusters were investigated (refs. 9 to 15). Initial thruster designs had an $I_{S p}$ goal of greater than $400 \mathrm{sec}^{l}$ and, thus, had mixture ratios from $3: 1$ to $5: 1$. Subsequent studies of propellant availability for various station fluid management strategies led to the requirement to operate at an 8:1 mixture ratio with the products of water electrolysis and thus reduced the Isp goal to $346 \mathrm{sec}$. This led to the need for thruster design modifications and an experimental demonstration of the $8.9 \times 10^{6} \mathrm{~N}-\mathrm{s}$ design goal. These successful results have led to H/O propulsion being baselined for the high thrust function on the Freedom.

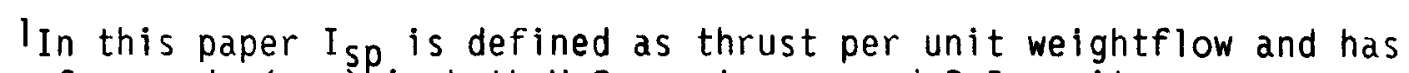
units of seconds $(\mathrm{sec})$ in both U.S. customary and S.I. units. 
Future launch vehicles. - Studies at NASA Lewis have shown that advanced auxiliary propulsion subsystems (APS) can significantly increase the payload of advanced ETO vehicles (refs. 16 and 17). The concept is based on using an integrated $\mathrm{H} / \mathrm{O}$ propulsion system in which propellants scavenged from the launch vehicle would be used for a liquid hydrogen/liquid oxygen $\left(\mathrm{LH}_{2} / \mathrm{LO}_{2}\right)$ primary reaction control system (RCS) and a gaseous hydrogen/gaseous oxygen $\left(\mathrm{GH}_{2} / \mathrm{GO}_{2}\right)$ vernier RCS. Unlike previous studies conducted during the space transportation system (STS) technology program, these studies have avoided any propellant conditioning requirements and have suggested the development of hardware to use the propellants in the as-delivered state. Figure 3 shows the proposed integrated H/O system in comparison with a 1960's vintage RCS concept.

The advantages of the currently proposed system include: (1) greater (by about $100 \mathrm{sec}$ ) system specific impulse; (2) simplified system through elimination of heat exchanger/gasifier, gas accumulator, and compressor; and (3) a decoupled thruster/propellant management system. Figure 4 shows the payoff in terms of increased payload mass for the integrated H/O system. A potential payload benefit of $4800 \mathrm{~kg}$ is projected for Space Shuttle 11. Such a payload benefit may also offer significant operational benefits in terms of the types of orbits that can be used. An industry study to verify these potential benefits is being initiated by NASA Lewis.

\section{Rocket Fundamentals}

Present computer codes do not correctly predict the performance of small rockets. As a result, NASA Lewis has significantly modified a National Aerospace Plane (NASP) combustor code and extended it to space station H/O rockets. This code offers the advantage of including the effects of a shear layer to cool the nozzle (for a small rocket the boundary layer is not so thin in relative terms) and of not having numerical "patches" at the throat. The initial outputs of the code include combustion shear layer mixing, transonic flow, and viscous nozzle flows. The results are encouraging and NASA Lewis will work with NASA's Ames Research Center (ARC) to use the computational capability of the National Aerospace Simulator (NAS) for the continuing work (ref. 18).

\section{ELECTROTHERMAL}

Electrothermal propulsion using subkilowatt resistojets is currently performing north-south stationkeeping (NSSK) on geosynchronous (GEO) satellites (refs. 19 and 20) and will be used for Freedom and man-tended platforms (ref. 2). The NASA electrothermal auxiliary propulsion program includes the development of resistojet options for high specific impulse and for long duration compatibility with multiple propellants. Kilowatt-class arcjets are being developed to provide increased life for higher power geosynchronous satellites. Power electronics technology is required for all these concepts and is, therefore, an integral part of the program, as it is also in the high power, primary propulsion area.

\section{Arcjets}

l-kW preflight development. - NASA Lewis has been studying arc physics; electrode materials and their compatibility with propellants; heat transfer, 
plasma arc, and fluid mechanics models. The NASA Lewis experiments have included plume fundamentals, arc/flow stability, and thruster/power processor integration fundamentals. NASA is working toward a flight test of an arcjet in the early 1990's. NASA Lewis successfully completed a 1000-hr, 500-cycle life test of a 1.3-kW arcjet this past year, thereby demonstrating system autonomy (ref. 21). No life-limiting mechanisms were identified as a result of the test. The arcjet met the pretest goals of 35 percent thrust efficiency and $450 \mathrm{sec}$ specific impulse. Figure 5 shows the specific impulse as a function of the ratio of the power. NASA Lewis also demonstrated reliable, consistent startups of the arcjet (refs. 22 and 23). Figure 6 shows the arc voltage as a function of cycle number; note that most of the voltage rise occurred in the initial 10-hr burn-in period (ref. 21).

Before arcjet technology can be applied to spacecraft, however, a number of spacecraft issues must be addressed. One of these is the thermal impact the arcjet will have on both the spacecraft and on the power connection to the power processing unit. NASA Lewis has been analyzing the thermal/mechanical interface between the arcjet and the spacecraft. The goal is to keep the back temperature low enough $(<400 \mathrm{~K})$ and the conducted heat low enough $(<10 \mathrm{~W})$ to minimize problems in designing the rear electrical connector. An obvious approach would be to extend the lengths of the arcjet; however, the structural analysis showed that the arcjet cannot be made long enough to get the desired temperature because of excessive heat losses. This pointed out the need for high emissivity surfaces. Further analyses showed that a coating such as zirconium diboride with an emissivity of about 0.6 would meet the thermal interfaces (ref. 24).

Under NASA Lewis contract, supported by the OAST Flight Projects office, Rocket Research Co. has fabricated a flight-type, kilowatt-class arcjet, which is shown in figure 7 . The electrode configuration has been verified by performance demonstrations and life testing. The arcjet has been successfully integrated with the power processing unit (PPU) and has met the thermal interfaces. The dynamic structural analysis of the arcjet has been completed and the electromagnetic effects on satellite communications have been assessed.

While many major issues such as electrode life and reliability have been addressed (e.g., ref. 21) little has been done to improve the efficiency of the device. Preliminary experimental work has shown that the operating characteristics of arcjets depend on the location of the arc attachment zone in the anode/nozzle. An anode/nozzle consisting of five pieces of tungsten insulated from each other by boron nitride spacers was used in a radiation-cooled, segmented anode to study the physics of the arc attachment zone (ref. 25). Large potential gradients were shown to exist in the nozzle during operation with all the segments attached to a common point. Preferred modes of operation were identified by forcing the point of attachment to different positions. Further, use of the segments as floating probes gave rough estimates of plasma potential, and, by subtraction, the anode drop. A knowledge of the fundamental of arcjets is important because of the existing low efficiency ( 33 to 38 percent) of arcjets caused, in part, because it expends so much energy in breaking bonds leading to a "frozen flow" with about 80 to 85 percent of the energy in the gas itself. Computationally. nozzle studies are difficult because of the extremely small dimensions, low Reynolds number operation, and complicated arc physics in the constrictor/nozzle region. The plasma and flow fields are strongly coupled, which complicates the analyses. Figure 8 shows that the nozzle geometry affects the arcjet characteristics (ref. 26). While the performance is 
insensitive to the upstream design of the thruster, it appears that a conicaldiverging nozzle is the optimum design.

As part of its effort to understand the fundamentals of arcjet (and ion engine) performance, NASA Lewis has established a laser-induced fluorescence (LIF) facility and is now identifying the plume species as part of its investigation of the electrode losses and spacecraft interactions. Under internal funding, JPL will be measuring the velocity and temperature profiles in the exhaust stream of a $30-\mathrm{kW}$ arcjet using LIF. Figure 9 shows the JPL LIF experimental setup (ref. 27).

Plume impacts. - As the arcjet thruster moves closer to being a flightready propulsion system onboard communications satellites for applications such as NSSK, spacecraft integration concerns become of significant interest. A key issue centers on the potential impact that the arcjet plume may have on the transmission of RF signals in common use for satellite communications. A first order study using Langmuir probe data indicated that the impacts appear negligible in the antenna far field, except for propagation paths near the arcjet source (ref. 28). More rigorous numerical techniques are necessary to fully define the interaction processes and effects which would occur if the plasma were to expand within the antenna near field. Recent results (ref. 29) extend the previous work and present a body of systematic experimental data which correlate measured plasma properties in the arcjet plume with a wide range of thruster operating conditions and constrictor geometries and confirm the earlier finding that communications impacts should be negligible.

5-kW System technoloqy. - Recent interest in arcjets has led to the development and life tests of both 1 and $30 \mathrm{~kW}(\mathrm{e} . \mathrm{g} .$, ref. 30 ) arcjet systems for application to GEO satellite stationkeeping and prime propulsion. Orbit transfer missions from LEO to GEO might significantly benefit from arcjet systems in the 5-kW power range coupled with the use of high thrust chemical hydrazine propulsion to rapidly transverse the Van Allen radiation belts. The low thrust, high $I_{s p}$ hydrazine arcjet system would then be used to complete the orbit raising and inclination changes required to achieve geosynchronous orbit. Such high-power arcjet systems will likely be energized from highvoltage buses since high bus voltage results in low spacecraft power system mass.

A 5-kW class arcjet system was recently developed at NASA Lewis (ref. 31) using a full-bridge, pulse-width-modulated power converter with electrical isolation. Previously, a $1-k W$ class pulse-width modulated parallel converter was used. For high bus voltages, a bridge converter has advantages over the parallel converter. The bridge converter power transistor switches operate at bus voltage whereas the parallel converter transistor switches must support twice the bus voltage. This advantage is partially offset by having two switches in series, but lower voltage transistors also have lower on resistance. Another advantage of the bridge converter is that the power transformer is simpler and lower mass than the parallel converter power transformer. The laboratory 1-kW, radiation-cooled arcjet used for this work is an extension of a design described elsewhere (ref. 21). Specific differences from the 1-kW class arcjet include modifications in the cathode, constrictor, and thruster heat radiating area. 
Resistojets

High performance. - To advance storable propellant resistojets beyond the current state-of-the-art $300 \mathrm{sec}$ mission-averaged I sp (ref. 32), several efforts have been undertaken. NASA Lewis is working through a four-phase contracted industrial development program to design, fabricate, and characterize a hydrazine resistojet thruster capable of about $320 \mathrm{sec} \mathrm{I}_{\mathrm{sp}}$. The first phase, which was conceptual design and analysis, has been completed and Rocket Research was chosen for the design finalization and performance characterization. Currently the program is assessing the tradeoff on immersed heaters versus radiatively-coupled heaters. Improved heat exchanger performance, longer-life higher-temperature heaters (refs. 33 and 34), and improved nozzle performance (refs. 35 and 36) are being sought. The importance of high quality test facilities for evaluating performance has been demonstrated (ref. 37 ).

NASA Lewis has been modeling the supersonic viscous flow in a resistojet by solving the Navier-Stokes equation in conservative form with a finite-volume formulation. A typical solution is shown in figure 10, which gives a plot of Mach number contours for an axisymmetric converging-diverging nozzle with a $20^{\circ}$ divergent half-angle, area ratio of 20 , and 1086 Reynolds number (ref. 38 ).

Multipropellant. - As previously mentioned, multipropellant resistojets have been baselined for Freedom. The requirements are quite different from most other propulsion applications in that long life and integration features are much more important than performance (refs. 9 to 11). Utilizing Freedom wastes as propellant minimizes resupply requirement and may eliminate the need to return some wastes to Earth. Engineering model thrusters have been built and delivered to NASA for testing (ref. 39). Performance characteristics on a wide range of possible propellants have been obtained (ref. 40), and long-term life tests have been conducted for over $10000 \mathrm{hr}$ with over 140 deep thermal cycles (ref. 41). A power controller was developed to enable the freedom resistojets to operate on high-frequency power (ref. 42 ). To facilitate the integration of this technology on Freedom, propellant and feed system options were assessed (ref. 43), and interfaces were defined (ref. 44). The exhaust plumes of the thrusters are of concern because of potential effects on sensors and experiments and potential attenuation of signals propagating through the plume. Analytical and experimental techniques have been developed ( $r e f .45$ ), and a preliminary assessment made of the effect of nozzle geometry on plume characteristics (ref. 46). The exhaust of the engineering model resistojet was investigated using rotary pitot probes and a rotating quartz crystal microbalance. The effect of a plume shield has been evaluated and found to be small, but the absolute mass flux into the backflow region was very low $\left(\sim 7 \times 10^{-7} \mathrm{~g} / \mathrm{cm}^{2}-\mathrm{sec}\right)(\mathrm{ref} .47)$.

Water. - Interest in water resistojets developed as a spin-off to the Freedom multipropellant resistojet development. For man-tended, shuttleserviced platforms such as the proposed industrial space facility (ISF), ease and safety of propellant resupply and ground handling operations are critical issues, which leads to interest in water as a propellant. With a resistojet capable of steam operation already under development for Freedom. water resistojets were baselined for the ISF (ref. 48). This necessitated the development of a zero-gravity steam generator when it was determined that available steam generators, such as that developed for the Manned Orbiting Research Laboratory, did not perform stably and reliably and that operation of the Freedom 
resistojet with liquid water feed could be quite unstable (ref. 40). A cyclone steam generator was developed after evaluation of a number of boiler concepts studied for space power application. Further development of this concept led to an integrated vaporizer/resistojet utilizing a single heater (ref. 49).

This concept is shown in figure 11; the liquid water is swirled to the outer wall and boiled by heat radiated from the central heater which also heats the resistojet by conduction. Thermal losses are reduced since the outer water operates at temperatures below saturation. This design also overcomes the many stability and phase separation problems typically encountered in zero-gravity boilers. Laboratory models have been built and performance mapped over a range of conditions, and flow visualization results obtained (ref. 50). Initial studies of the plume characteristics of steam resistojets has recently been conducted (ref. 51). Mass flux and flow angle measurements were obtained in the plume using a variable temperature quartz crystal microbalance.

\section{PRIMARY (HIGH POWER) ELECTRIC}

Prospects now appear good for broad acceptance and application of electric propulsion systems (ref. 20). However, current applications are limited to low-power stationkeeping and orbit control (refs. 19, and 52 to 54). The successful operation of these systems has led to increased user confidence, and further operational use of electric propulsion appears imminent.

The National Commission on Space advocated a number of challenging missions, such as a return to the Moon, unmanned and manned exploration of Mars and its moons, and unmanned scientific exploration of the rest of the solar system (ref. 55). Many of these missions would be enhanced, and some would be enabled by high $I_{s p}$ electric propulsion. To perform the challenging future missions, high power and high $I_{\text {sp }}$ systems will be required. Candidate systems include electrostatic (ion) and MPD engines, with electrodeless approaches representing a longer term possibility. Electric propulsion is also applicable to advanced robotic exploration missions, offering both decreased propellant mass (and/or increased payload) and reduced trip times for deep space missions. Furthermore, this technology may be applicable to manned spacecraft using artificial gravity, where speed is not so critical. There are also many potential applications for high Isp electric propulsion at the tens of kilowatts available from large solar power systems. High specific impulse clearly offers propellant mass savings, but in order to practically exploit that benefit for space missions, it is necessary for the overall vehicle to exhibit acceleration levels sufficient to meet mission time lines. This requirement necessitates low specific mass and high efficiency propulsion and power systems in order to keep power system mass low.

\section{Mission and System Analyses}

Mission analyses covering spacecraft from small, solar electric propulsion (SEP) (refs. 2 and 56) to large, megawatt nuclear electric propulsion (NEP) spacecraft (refs. 57 to 61) show enhancing to enabling levels of capability for exploration of the planets and beyond (ref. 52). JPL considered a smal1, 180-kg demonstration spacecraft with a 1.5-kWe solar array using ion propulsion for transportation from LEO to lunar orbit (ref. 56). This Lunar Get Away Special (LGAS) mission would carry one instrument, nominally an Apollo gamma ray spectrometer, and would carry $36 \mathrm{~kg}$ of xenon propellant. JPL has 
also studied a deep space mission concept, wherein the Thousand Astronomical Unit (TAU) Explorer, propelled by NEP, would reach 1000 A.U. in 50 years with a significant science payload (ref. 57). Both of these spacecraft accomplish the mission propulsion with a minimum of propellant mass and, thereby, maximize the science payloads at their destinations. A study was conducted by JPL (ref. 60) of the benefits ion propulsion might provide to the CRAF mission if it were used instead of storable bipropellants. Even though the mission and its science package were not optimized for use of electric propulsion, a 3-year trip time reduction could be achieved along with a 600-kg increase in launch mass margin.

A range of solar-and nuclear-powered Earth orbital missions have been studied and show cost/mass reductions benefits (refs. 62 to 64). In a USAF study it was shown that a solar electric orbit transfer vehicle for delivery of satellite constellations to their operational orbits could offer significant savings (ref. 62).

Nuclear electric propulsion system technology for an electric cargo vehicle has been identified as a major requirement for evolutionary solar system exploration (ref. 65). The use of an electric, low-thrust cargo vehicle in the Lunar Outpost to Early Mars Evolution case could potentially reduce the initial mass in LEO (IMLEO) by one-third over a standard chemically propelled vehicle. Studies have shown that for a Mars cargo vehicle large enough to support a manned mission, high performance electric propulsion with specific impulses over $4000 \mathrm{sec}$ at multimegawatt power levels can offer major reductions in propellant requirements at acceptable transit times. Compared with an aerobraking cargo vehicle using hydrogen/oxygen propulsion, and nonaerobraking high performance electric vehicle can result in elimination of at least three Heavy Lift Launch Vehicle (HLLV) launches, and savings are even greater when compared with nonaerobraking chemical propulsion (ref. 66). This reduction in the number of launches might permit the mission to be completed more rapidly if HLLV launch rates are low. To perform these challenging future missions, the total impulse capability must be advanced from the currently demonstrated $10^{6} \mathrm{~N}-\mathrm{s}$ for both ion and MPD engines to at least $10^{8} \mathrm{~N}-\mathrm{s}$ (ref. 67).

\section{Ion}

Ion engines have demonstrated specific impulses from less than $2000 \mathrm{sec}$ to more than $10000 \mathrm{sec}$, thrust efficiencies to over 0.75 (e.g., ref. 68), and total thrust impulse as high as $10^{6} \mathrm{~N}-\mathrm{s}$ for $10-\mathrm{kW}$ class thrusters. Propellants have included mercury, argon, krypton, and xenon. Ion thruster technology has been demonstrated with flight testing of the Space Electric Rocket Test (SERT 1, 11) ion thrusters (ref. 69). Electrostatic (ion) propulsion is planned for its first operational use on the Japanese Engineering Test Satellite VI (ref. 54). Thruster size is adjustable to fit mission requirements (fig. 12). But to advance to significantly higher power, the key issues are scale-up of ion acceleration subsystems for high power operation and thruster life. High power operation is limited by ion optics, and extraction area must be increased with increasing power. Ion propulsion systems in the range of 10 to 50-kW offer significant payload and trip time advantages over chemical systems for lunar ferry and outer planet explorer missions (including multiple target missions), as well as for missions outside the solar system A nearterm target for planetary and Earth orbital missions is about 5 to $30 \mathrm{~kW}$ per ion thruster using xenon as a propellant. The planned Pathfinder Cargo Vehicle 
Propulsion program will focus on a target of 0.1 to 1 MW per ion thruster using argon or krypton. While the performance engineering of ion engines is well in hand the scalability, system, lifetime, and power processing issues remain open and are being addressed in the NASA program.

Lifetime. - Interest in near-term application of ion thrusters for solar electric propulsion in near-Earth missions (refs. 62 and 70) has led to a program to identify and extend the operating limits of ion thrusters originally developed for 3-kW operation with mercury to the 10-kW range using inert gas propellants (refs. 71 and 72 ). The original mercury ion engines presented life limiting phenomena like spalling of metal flakes eroded from the discharge chamber surfaces which could short out the screen accelerating grids as well as the problem of using a toxic, condensible propellant. As a result the program is now focused on inert gas propellants, primarily xenon. JPL modified the $0.3-\mathrm{m}$ J-series mercury ion engines, which had previously been highly developed and were ready for space qualification testing at $2.2 \mathrm{~kW}$, to use xenon. Recognizing that the xenon sputter rates are greater than for mercury and the xenon engine operating powers are 2 to 5 times those for mercury engines, lifetime is a critical issue. An ion thruster system for planetary applications has been designed and is undergoing engineering tests (ref, 73). The focus of these activities is on reducing system complexity, with the goal of reducing the cost of development and flight qualification. Proposed design changes are evaluated in terms of mission impact (ref. 74).

To overcome cathode erosion problems, JPL has been te ting a $1.27-\mathrm{cm}$ diameter hollow cathode shown in figure 13 (ref. 75). The cathode was successfully operated for $1200 \mathrm{hr}$ on argon, of which $1050 \mathrm{hr}$ were at $100 \mathrm{~A}$ and $24 \mathrm{hr}$ were at $150 \mathrm{~A}$. The cathode was still operating when the testing was terminated; cracking along the tantalum barrel at the upstream end and tungsten deposits which were in the process of closing off the insert bore were two of the problems observed in operating these cathodes at high power. There may have been a cathode jet formed which could have been responsible for the high erosion rate at the upstream side of the baffle. Preliminary data obtained by JPL in 1987 showed that the introduction of nitrogen into the xenon propellant reduced the baffle erosion. Nitrogen may also reduce the erosion of the accelerating grids. The work will be continued (ref. 76). In addition, alternatives to tantalum will be tested as baffle materials and erosion and deposition rates on critical surfaces and deposit structure will be characterized.

Scaling issues. - Results have previously been reported for 30 - to $50-\mathrm{cm}$ diameter xenon thrusters at power levels up to $20 \mathrm{~kW}$. However, the only extended operation of a high power xenon ion thruster has been with a $30-\mathrm{cm}$ J-series divergent-field thruster at $10 \mathrm{~kW}$. This thruster had insufficient life for high total impulse mission because of cathode baffle erosion. NASA Lewis has addressed its cathode-baffle erosion, which was running about $0.5 \mathrm{~mm} / \mathrm{hr}$, by eliminating the baffle/pole piece and going to the ring cusp design shown in figure 14 . This design will require the application of a magnetic field on the order of 500 to $1000 \mathrm{G}$ at the boundary (refs. 77 and 78). Measurements made by NASA Lewis have shown that the erosion rates are very sensitive to the discharge current. In order to understand erosion better, NASA Lewis is developing a model of sputtering.

NASA Lewis has demonstrated the technology to fabricate $0.5-m$ ion thrusters (ref. 79) as shown in figure 15. Figure 16 shows the ion beam extraction capability of a $0.3-\mathrm{m}$ ion engine and the new $0.5-\mathrm{m}$ ion engine. The $0.5-\mathrm{m}$ 
engine doubles the power capability and extends the specific impulse capability. (The thruster efficiency is nearly independent of size and magnetic circuit.)

Early ion thruster grids (ion optics) were flat and were subject to severe, uncontrolled buckling when radial temperature gradients became too steep. The grids were then dished to control buckling. Increasing the thrust of ion engines will require increasing grid size. With the larger grids and potentially noncircular geometries now under consideration, computer modeling has been developed and experimentally verified for understanding structural response (ref. 80 ).

Engine system technoloqy. - JPL has been working on a simplified system design and improving throttling strategy for planetary mission. As shown in figure 17, JPL has determined that ion engines operating at fixed propellant flow rates can be throttled over an input power range of $3.2: 1$ with only a small increase in propellant consumed and small decrease in payload delivered as compared to operating the engines at a variable flow rate. The improved throttling strategy seeks to select the most optimum number of operating engines, operational duty cycles, and specific impulse. The systems studies have shown that this optimized throttling strategy results in a reduction in the required engine lifetime of 25 percent to perform the base mission, which was a rendezvous with Comet Kopff, when compared to the conventional throttling technique. Obviously the constant flow strategy eliminates the flow controllers and permits operation at fixed discharge conditions - and it may also simplify the PPU. JPL plans to configure the laboratory PPU for a twoengine operation and operate the two-engine module on a single screen supply. Computer control algorithms for multiengine control will be developed.

NASA Lewis has examined in parametric fashion the impact of various thruster technologies and operating conditions and system technologies on the design and performance of a $10-k W$ class ion propulsion system for orbital maneuvering and transfer. A methodology is described wherein a computer code is used for precise determination of ion thruster performance (based upon predefined and user-defined thruster technologies), a determination of overall propulsion system design including a complete mass breakdown. and first-order calculations of total impulse and delta-V capabilities. Results are obtained from this code to examine the impact of thruster technologies (engine diameter, 2- and 3-grid ion optics, thruster operating conditions (power level propellant, and specific impulse), and subsystem technologies on system design and mission capability. These analyses were also conducted for arcjet systems (ref. 81).

\section{MAGNETOPLASMADYNAMIC}

Multimegawatt MPD thruster technology offers payload gains of a factor of 10 over chemical propulsion for typical orbit raising, lunar base ferry, and manned interplanetary missions. The MPD thruster combines high specific impulse ( 1000 to $5000 \mathrm{sec}$ ) with moderate thrust levels ( 10 to $100 \mathrm{~N}$ ). Historically, steady state MPD thrusters have typically been run at or below the few hundred kilowatt range (e.g., refs. 82 to 84), while MPD thrusters operated in a pulsed mode have been run at power levels exceeding 1 MW (e.g., refs. 84 to 87). Propellants have included $\mathrm{H}_{2}, \mathrm{Ar}$, $\mathrm{He}, \mathrm{Li}, \mathrm{Ne}, \mathrm{NH}_{3}$, and $\mathrm{N}_{2} \mathrm{H}_{4}$. 
High specific impulse ( 3000 to $6000 \mathrm{sec}$ ) at efficiencies of 30 to 50 percent have been demonstrated using hydrogen (e.g., refs. 88 and 89), though in general thrust efficiencies have not exceeded 30 percent for most propellants (fig. 18). Presently, MPD thruster lifetimes are limited by severe cathode erosion (refs. 90). MPO propulsion is less advanced than ion. Higher efficiencies and specific impulses are generally obtained with applied magnetic fields, but the fundamental theoretical understanding of this mode of operation is lacking. The highest total impulse demonstrated is $10^{6} \mathrm{~N}-\mathrm{s}$, at about $25 \mathrm{~kW}$ (ref. 91).

Currently, NASA Lewis is involved in both experimental and theoretical research in the areas of cathode erosion and MPD thruster performance. NASA Lewis has made operational its high-power MPO thruster test stand and successfully demonstrated an operating power of $130 \mathrm{~kW}$ in a hybrid MPD/electrothermal mode and $60 \mathrm{~kW}$ in the MPD mode (ref. 91) NASA Lewis has extended the magnetic field to $0.3 \mathrm{~T}$ and shown reduced anode damage on start-up and an extended stable steady-state operating range as shown in figure 19 (refs. 92 and 93). A high-power MPD thrust stand (ref. 94) and nonintrusive plasma diagnostics (ref. 95) are being developed, and hardware is being assembled for a series of cathode erosion experiments. Codework is being written to simulate the magnetoplasmadynamic interactions (ref. 96), and will be used to evaluate thruster design changes (ref. 90). JPL is also working on such a test stand and both Centers are developing nonintrusive diagnostics for MPD testing. The potential impact of high-temperature superconductivity developments on MPD technology was assessed in a joint effort by Argonne National Laboratory and NASA Lewis (ref. 97).

Work at JPL has demonstrated that cathode evaporation can be minimized by designing for thermionic emission during steady-state operation. This may lead to practical thruster lifetimes $(>1000 \mathrm{hr}$ ). In the near term, JPL is focusing on demonstrating MPD thruster operation for periods greater than $100 \mathrm{hr}$. Previously, using the thruster concept shown in figure 20, JPL had completed 85 runs totaling $13 \mathrm{hr}$ of operation, reaching a maximum power of over $72 \mathrm{~kW}$ at $2245 \mathrm{~A}$. The engine operated for an 83-min period with no excessive arc spot damage on the cathode. The cathode tip temperature was less than $2240 \mathrm{~K}$ for operation up to $1700 \mathrm{~A}$ with an argon propellant mass flow rate of $0.16 \mathrm{~g} / \mathrm{sec}$.

JPL has observed two distinct steady-state operating modes as shown in figure 21. The first mode is characterized by a luminous cathode jet while the second mode has a cooler cathode tip and no cathode jet. At the same current the terminal voltage is as much as 40 percent lower in the second mode. It may turn out that the second mode could provide the more efticient acceleration of the plasma, due to a more contained radial current pattern. Work is continuing to understand the conditions under which the two modes occur.

As part of its effort to improve MPD thruster performance JPL has designed a radiation-cooled, applied field hybrid engine as shown in figure 22 . This will be fabricated and tested. JPL has also been reviewing the literature to determine if designs previously discarded because of the previously existing technology limitations may now be useful. Recognizing that electrode sheaths have a significant effect on MPD thruster operational limitations and performance, JPL is sponsoring the development of a more sophisticated twodimensional model that will provide a better understanding of MPD thruster operations than current one-dimensional models. 


\section{ELECTRODELESS DISCHARGE THRUSTERS}

Electrode thruster concepts offer the potential for very high energy coupling efficiency, and are therefore, of great interest for high power applications (refs. 98 to 104). Limitations imposed by electrode erosion in other electric propulsion thruster designs are potentially avoided.

Currently NASA Lewis is evaluating the microwave electrothermal (MET) thruster (ref. 90), which absorbs applied microwave power in a plasma discharge and heats the gas propellant by high pressure thermalization (fig. 23). Advantages include a high efficiency for power absorption; a high power density; and external control of the discharge location, shape, and volume. The MET thruster should readily scale with power (although performance may not) and it is compatible with high power operation. The current technology MET, being developed in conjunction with Michigan State University, operates at a microwave frequency of $2450 \mathrm{MHz}$ and a power coupling efficiency in excess of 95 percent. Power levels up to $2.5 \mathrm{~kW}$ have been tested, and specific impulse values up to $600 \mathrm{sec}$ have been obtained with helium. Recent results show energy efficiencies approaching 65 percent at low power (ref. 105). Gases tested include $\mathrm{He}, \mathrm{N}_{2}, \mathrm{H}_{2}$, and $\mathrm{O}_{2}$, and a varlety of microwave applicator designs have been demonstrated. Present limitations in performance are due to material constraints and MET throat/nozzle design (ref. 90).

Future work at NASA Lewis will focus on power levels of $30 \mathrm{~kW}$ at a frequency of $915 \mathrm{MHz}$, using $\mathrm{H}_{2}$, He, and $\mathrm{N}_{2}$ at discharge pressure up to $10 \mathrm{~atm}$. A magnetic nozzle, produced by a low temperature superconducting magnetic magnet (peak field $5.7 \mathrm{~T}$ ), will be used to increase the plasma density in the discharge chamber walls. Computer modeling will be used to predict performance with magnetic nozzles, and to compare performance limits with other electrodeless concepts including electron cyclotron resonance (ECR) and ion cyclotron resonance (ICR) heated thrusters (refs. 90, 99, 105, and 106)). JPL is also conducting research on the ECR concept (ref. 104).

\section{ELECTROMAGNETIC LAUNCHERS}

The possible application of electromagnetic launchers to deliver nonfragile materials from the Moon to LEO or other nodes was suggested by the National Commission on Space (ref. 55). Several years ago NASA Lewis completed an investigation of electromagnetic launchers for delivery of nonfragile payloads from Earth into various orbits (refs. 107 to 109). These studies indicated significant cost benefits for Earth-based launchers if the launch rate of appropriate cargo is high enough. Studies have also considered the utility of EML's for the launch of raw materials and nonfragile cargo from the lunar surface (refs. 110 to 113). However the launch rates would have to be higher than those envisioned in any of the exploration case studies before an Earth-to-space rail launcher would be competitive with chemical launchers. Advances in high temperature superconductivity could contribute significantly to the utility of such launchers (ref. 114) and make them the most economical means of bulk transport from the surface of the Moon for such materials as propellants (ref. 115). 


\section{CONCLUDING REMARKS}

The ongoing NASA program in low-thrust primary and auxiliary propulsion continues to make great strides. The development of high-temperature chemical thrusters offers order-of-magnitude lifetime improvements and higher specific impulses. The technology for resistojets has been taken to the point where they are baselined for space station. Work is advancing on arcjets leading to a planned flight demonstration. Both ion and MPD thruster technology issues are being addressed with the goal to flight demonstrate these systems so they will be ready for future missions such as a cargo vehicle flight to Mars.

\section{ACKNOWLEDGMENTS}

The authors acknowledge the contributions made by P. Garrison, J. Kelley, D. King, T. Pivirotto, J. Barnett, K. Goodfellow, W. Deininger, and C. Garner of JPL and by D. Byers, F. Curran, R. Myers, S. Schneider, J. Sovey, and $L$. Carney of NASA Lewis. The authors also acknowledge the continued support of $G$. Reck and $E$. VanLandingham of NASA Headquarters which allowed us to complete this paper.

\section{REFERENCES}

1. Reck, G.M., "NASA Directions in Space Propulsion for 2000 and Beyond," NASA TM-102281, 1989.

2. Palaszewski, B., and Engelbrecht, C., "Lightweight Spacecraft Propulsion System Selection," AIAA Paper 87-2022, July 1987.

3. Stone, J.R., "Recent Advances in Low Thrust Propulsion Technology," AIAA Paper 88-3283, July 1988.

4. Whalen, M.V., Lansaw, P.T., and Wooten, J.R., "High Temperature, Oxidation Resistant Thrusters," 1987 JANNAF Propulsion Meeting, Vol. 1, CPIA-480VOL-1, P.S. Eggleston and K.L. Strange, eds., Chemical Propulsion Information Agency, Laurel, MD, 1987, pp. 413-420.

5. Harding, J.T., Kazaroff, J.M., and Appe 1, M.A., Iridium-Coated Rhenium Thrusters by CVD, NASA TM-101309, 1988.

6. Wooten, J.R., and Lansaw, P.T., "High-Temperature, Oxidation-Resistant Thruster Research," Aerojet TechSystems Co., Sacremento, CA, NASA Contract NAS3-24643, (NASA CR, to be published, 1989).

7. Appe 1, M., Schoenman, L., Franklin, J., and Lansaw, P.T., "Feasibility Demonstration of 445-N High Performance Rocket Engine, "Proposed for the 1389 JANNAF Propulsion Meeting, Cleveland, OH, May 1989.

8. Meng, P.R., Schneider, S.J., Morgan, C.J., Jones, R.E., and Pahl, D.A., "A Life Test of a 22 Newton (5-1bf) Hydrazine Rocket," NASA TM-100232, 1987.

9. Jones, R.E., "High and Low-Thrust Propulsion Systems for the Space Station," AIAA Paper 78-0398, Jan. 1987, (NASA TM-88877). 
10. Jones, R.E., Meng, P.R., Schneider, S.J., Sovey, J.S., and Tacina, R.R., "Space Station Propulsion System Technology," Acta Astronautica, Vol. 15, No. 9, Sept. 1987, pp. 673-683.

11. Jones, R.E., Morren, W.E., Sovey, J.S., and Tacina, R.R., "Space Station Propulsion," NASA TM-100216, 1987.

12. Heckert, B.J., Yu, T.I., Allums, S.L., and Carrasquillo, E.A., "25th lbf Gaseous Oxygen/Gaseous Hydrogen Thruster for Space Station Application," 1986 JANNAF Propulsion Meeting, Vol. 1, K.L. Strange and D.S. Eggleston, eds., CPIA-PUBL-455-VOL-I, Chemical Propulsion Information Agency, Laurel, MD, 1986, pp. 539-546.

13. Robinson, P.J., and Rosenthal, S.E., "A Proven 25-lbf $\mathrm{H}_{2} / \mathrm{O}_{2}$ Thruster for Space Station Auxiliary Propulsion," AIAA Paper 86-1560. June 1986.

14. Senneff, J.M., and Richter, G.P., "A Long-Life 50 lbf $\mathrm{H}_{2} / \mathrm{O}_{2}$ Thruster for Space Station Auxiliary Propulsion," AIAA Paper 86-1404, June 1986.

15. Richter, G.P., and Price, H.G., "Proven, Long-Life Hydrogen/Oxygen Thrust Chambers for Space Station Propulsion," 1986 JANNAF Propulsion Meeting, Vol. 1, K.L. Strange and D.S. Eggleston. eds., CPIA-PUBL-455-VOL-I, Chemical Propulsion Information Agency, Laure1, MD, 1986, pp. 547-564 (NASA TM-88822).

16. Schneider, S.J., "Auxiliary Propulsion Technology for Advanced Earth-toOrbit Vehicles," NASA TM-100237, 1987.

17. Schneider, S.J., and Reed, B.D., "Weight Savings in Aerospace Vehicles through Propellant Scavenging," SAWE Paper 1818, Society of Allied Weight Engineers, May 1988 (NASA TM-100900).

18. Schneider, S.J., Personal Communication, NASA Lewis Research Center, Cleveland, $\mathrm{OH}, 1988$.

19. Sackheim, R.L., and Howell, G.W., "Trends in Propulsion Systems for Geosynchronous Satellites," 14th International Symposium on Space Technology and Science, M. Nagatomo, ed., AGNE Publishing, Tokyo, Japan, 1984, pp. 245-254.

20. Byers, D.C., and Wasel, R.A., "The NASA Electric Propulsion Program," AIAA Paper 87-1098, May 1987 (NASA TM-89856).

21. Curran, F.M., and Haag, T.W., "An Extended Life and Performance Test of a Low-Power Arcjet," AIAA Paper 88-3106, July 1988 (NASA TM-100942).

22. Haag, T.W., and Curran, F.M., "Arcjet Starting Reliability: A Multistart Test on Hydrogen/Nitrogen Mixtures," AIAA Paper 87-1061, May 1987 (NASA TM-89867).

23. Sarmiento, C.J., and Gruber, R.P., "Low-Power Arcjet Thruster Pulse Ignition," AIAA Paper 87-1951, June 1987 (NASA TM-100123). 
24. Curran, F.M., Bruckner, R., and Haag, T., "Low Power Arcjet Thermal Considerations," Proposed for the 1989 JANNAF Propulsion Meeting, Cleveland, $\mathrm{OH}$, May 1989.

25. Curran, F.M., and Manzella, D.H., "The Effect of Electrode Configuration on Arcjet Performance," AIAA Paper 89-2722, July 1989.

26. Curran, F.M., Sovie, A., and Haag, Thomas, "Arcjet Nozzle Design Impacts," NASA TM-102050, 1989 (Proposed for the 1989 JANNAF Propulsion Meeting).

27. Deininger, W.D., Personal Communication, Jet Propulsion Laboratory, Dec. 1988.

28. Carney, L.M., "Evaluation of the Communications Impact of a Low-Power Arcjet Thruster," AIAA Paper 88-3105, July 1988 (NASA TM-100926).

29. Carney, L.M., and Sankovic, J.M., "The Effects of Arcjet Thruster Operating Condition and Constrictor Geometry on the Plasma Plume," AIAA Paper 89-2723, July 1989.

30. Pivirotto, T.J., King, D.Q., Deininger, W.D., and Brophy, J.R., "The Design and Operating Characteristics of a 30-kW Thermal Arcjet Engine for Space Propulsion," AIAA Paper 86-1508, June 1986.

31. Gruber, R.P., and Haag, T.W., "A 5 kW Class Arcjet System," AIAA Paper 89-2725, July 1989.

32. Roberts, C.R., "Life Demonstration Test of an Uprated Augmented Catalytic Thruster," AIAA Paper 87-0996, May 1987.

33. Barr, F.A., and Page, R.J., "Slip Casting and Extruding Shapes of Rhenium with Metal Oxide Additives, Part II - Development of Grain Stabilized Rhenium Parts for Resistojets," NASA CR-180851, 1987.

34. Page, R.J., Stoner, W.A., and Barker, L., "Preliminary Design Study of Hydrogen and Ammonia Resistojets for Prime and Auxiliary Thrusters, NASA CR-182176, 1988.

35. Grisnik, S.P., Simith, T.A., and Saltz, L.E., "Experimental Study of Low Reynolds Number Nozzles," AIAA Paper 87-0992, May 1987 (NASA TM-89858).

36. Whalen, M.V., "Low Reynolds Number Nozzle Flow Study," NASA TM-100130, 1987.

37. Manzella, D.H., Penko, P.F., DeWitt, K.J., and Kieth, T.G., "An Experimental Investigation of the Effect of Test Cell Pressure on the Performance of Resistojets," AIAA Paper 87-3286, July 1988.

38. Penko, P.F., Smith, C.C., Dewitt, K.J., and Kieth, T.G., "A Numerical and Experimental Investigation of Resistojet Nozzle Flow, "AIAA Paper 89-2839, July 1989. 
39. Shephard, C.B., McKevitt, F.X., and Finden, L.E., "Multipropellant Resistojet," Rept. No. RI/RD88-150, Rockwell International, Rocketdyne Division, Canoga Park, CA, Oct. 1988, NASA CR-182199.

40. Braunscheidel, E.P., "Performance Characterization and Transient Investigation of Multipropellant Resistojets," AIAA Paper 89-2837, July 1989.

41. Tacina, R.R., Personal Communication, NASA Lewis Research Center, Cleveland, $\mathrm{OH}, \mathrm{Mar} .1989$.

42. Gruber, R.P., "Resistojet Control and Power for High Frequency AC Buses," AIAA Paper 87-0994. May 1987 (NASA TM-89860).

43. Heckert, B.J., "Space Station Resistojet System Requirements and Interface Definition Study," RI/RD87-109. Rocketdyne Division, Rockwell International Corp., Canoga Park, CA, Feb. 1987, NASA CR-179581.

44. Bader, C.H., "Potential Propellant Storage and Feed Systems for Space Station Resistojet Propulsion Options," NASA CR-179457, 1987.

45. Zana, L.M., Hoffman, D.J., Breyley, L.R., and Serafini, J.S., "An Analytical and Experimental Investigation of Resistojet Plumes," AIAA Paper 87-0399, Jan. 19B7 (NASA TM-88852).

46. Breyley, L.R., Serafini, J.S., Hoffman, D.J., and Zana, L.M., "Effect of Nozzle Geometry on the Resistojet Exhaust Plume," AIAA Paper 87-2121, June 1987.

47. Carney, L.M., and Bailey, A.B., "Experimental Evaluation of Resistojet Thruster Plume Shields," IEPC Paper 88-091, Oct. 1988 (NASA TM-101363).

48. Louviere, A.J., Jones, R.E., Morren, W.E., and Sovey, J.S., "WaterPropellant Resistojets for Man-Tended Platforms," IAF Paper 87-2519, Oct. 1987 (NASA TM-100110).

49. Morren, W.E., and Stone, J.R., "Development of a Liquid-Fed Water Resistojet," AIAA Paper 88-3288, July 1988 (NASA TM-100927).

50. Morren, W.E., and Stone, J.R., "Operational Characterizations of a LiquidFed Water Resistojet," AIAA Paper 89-2836, July 1989.

51. Manzella, D.H., and Carney, L.M., "Plume Impacts of a Liquid-Fed Water Resistojet," AIAA Paper 89-2840, July 1989.

52. Stone, J.R., Byers, D.C., and King, D.0., "The NASA Electric Propulsion Program," IEPC Paper 88-002, Oct. 1988 (NASA TM-101324).

53. Brill, Y., Ejsner, A., and Osborn, L., "The Flight Application of a Pulsed Plasma Microthruster. The NOVA Satellite," AIAA Paper 82-1956, Nov. 1982.

54. Shimada, S., Takegahara, H., Kimura, H., and Kajiwara, K., "Ion Engine System for North-South Station-Keeping of Engineering Test Satellite VI," AIAA Paper 87-1005, May 1987. 
55. Pioneering the Space Frontier, National Commission on Space, Bantam Books, New York, 1986.

56. Nock, K.T., Aston, G., Salazar, R.P., and Stella, P.M., "Lunar Get Away Special (GAS) Spacecraft," AIAA Paper 87-1051, May 1987.

57. Nock, K.T., "TAU - A Mission to a Thousand Astronomical Units," AIAA Paper 87-1049, May 1987.

58. Galecki, D.L., and Patterson, M.J., "Nuclear Powered Mars Cargo Transport Utilizing Advanced Ion Propulsion," AIAA Paper 87-1903, June 1987 (NASA TM-100109).

59. Sauer, C.G., Jr., "Application of Solar Electric Propulsion to Future Planetary Missions," P.IAA Paper 87-1053, May 1987.

60. Aston, G., "Advanced Electric Propulsion for Interplanetary Missions," Aerospace Century XXI: Space Flight Technologies, Advances in the Astronautical Sciences, Vol. 64, Pt. 2, Univelt Inc., San Diego, CA, 1987 , pp. 609-626.

61. Kerridge, S.J., and Atzei, A., "A Comet Nucleus Sample Return Mission," IAF Paper 87-447, Oct. 1987.

62. Sponable, J.M., and Penn, J.P., "Electric Propulsion for Orbit Transfer A NAVSTAR Vehicle for Case Study," AIAA Paper 87-0985, May 1987.

63. Schreib, R., "Utility of Xenon Ion Stationkeeping," AIAA Paper 86-1849, June 1986.

64. Deininger, W.D., and Vondra, R.J., "Electric Propulsion of Constellation Deployment and Spacecraft Maneuvering," AIAA Paper 88-2833, July 1988.

65. "Exploration Studies Technical Report - FY 1988 Status - Vol 1: Technical Status," NASA TM-4075-VOL-1, 1988.

66. Niehoff, J., "Humans on Mars: A Space Leadership Program," Briefing to NASA Headquarters, Science Applications International Corporation, 1987.

67. Sovey, J.S., and Mantenieks, M.A., "Performance and Lifetime Assessment of MPD Arc Thruster Technology," AIAA Paper 88-3211, July 1988 (NASA TM-101293).

68. Rawlin, V.K., and Patterson, M.J., "High Power Ion Thruster Performance," NASA TM-100127, 1987.

69. Kerslake, W.R., "Ion Propulsion for Spacecraft," NASA TM-79502, 1977.

70. Garner, C., "Ion Propulsion System Technology for Orbit Raising and Maneuvering," Proposed for 1989 JANNAF Propulsion Meeting, Cleveland, $\mathrm{OH}$, May 1989. 
71. Rawlin, V.K., "Internal Erosion Rates of a 10-kW Xenon Ion Thruster," AIAA Paper 88-2912, July 1988 (NASA TM-100954).

72. Patterson, M.J., and Rawlin, V.K., "Performance of 10-kW Class Xenon Ion Thrusters," AIAA Paper 88-2914, July 1988 (NASA TM-101292).

73. Aston, G., Brophy, J.R., Garner, C.E., and Pless, L.C., "Operating Characteristics of a 10-kW Xenon Ion Propulsion Module," AIAA Paper 87-1006, May 1987.

74. Garner, C.E., Brophy, J.R., and Pless, L.C., "Ion Propulsion System Design and Throttling Strategies for Planetary Missions," AIAA Paper 88-2910, July 1988.

75. Brophy, J.R., and Garner, C.E., "Tests of High Current Hollow Cathodes for Ion Engines," AIAA Paper 88-2913, July 1988.

76. Garner, C., "Techniques for Reduced Spalling and Increased Operating Life of Xenon Ion Engines," AIAA Paper 89-2714, July 1989.

77. Rawlin, V.K., "Performance of Large Area Ion Thrusters for Orbit Transfer Missions," NASA TM-102049 (1989 JANNAF Propulsion Meeting).

78. Patterson, M.J., and Verhey, T.R., "Performance and Lifetime Characterization of a $10 \mathrm{~kW}$ Xenon Ring-Cusp Ion Thruster," AIAA Paper 89-2713, July 1989.

79. Rawlin, V.K., and Millis, M.G., "Ion Optics for High Power $50 \mathrm{~cm}$ Diameter Ion Thrusters," AIAA Paper 89-2717, July 1989.

80. MacRae, G.S., "Structural Analyses of Ion Optical Systems Using the MARC Finite Element Code," AIAA Paper 89-2719, July 1989.

81. Patterson, M.J., and Curran, F.M., "Electric Propulsion Options for $10 \mathrm{~kW}$ Class Earth-Space Missions," Proposed for 1989 JANNAF Propulsion Meeting, Cleveland, OH, May 1989.

82. Auweter-Kurtz, M., Kurtz, H.L., Schrade, H.O., and Sleziona, P.C., "Numerical Modeling of the Flow Discharge in MPD Thrusters," AIAA Paper 87-1091, May 1987.

83. Kurtz, H.L., Auweter-Kurtz, M., Merke, W., and Schrade, H O., "Experimental MPD Thruster Investigations," AIAA Paper 87-1019, May 1987.

84. King, D.Q., and Brophy, J.R., "Design and Operation of a 100-kW, Subscale MPD Engine," AIAA Paper 87-1020, May 1987.

85. Myers, R.M., Suzuki, N., Kelly, A.J., and Jahn, R.G., "Cathode Phenomena in a Low Power, Steady State MPD Thruster," AIAA Paper 88-3206, July 1988.

86. Myers, R.M, Kelly, A.J., and Jahn, R.G., "Electrothermal-Electromagnetic Hybrid Thruster Research," AIAA Paper 87-1018, May 1987. 
87. Choueiri, E.Y., Kelly, A.J., and Jahn, R.G., "MPD Thruster Plasma, Instability Studies," AIAA Paper 87-1067, May 1987.

88. Yoshikawa, T., Kagaya, Y., Yokoi, Y., and Tahara, H., "Performance Characteristics of Quasi-Steady State MPD Thrusters," 17th International Electric Propulsion Conference, Japan Society for Aeronautical and Space Sciences, Tokyo, 1984, pp. 396-403.

89. Uematsu, K., Mori, K., Kuninaka, H., and Kuriki, K., "Effect of Electrode Configuration on MPD Arcjet Performance," 17 th International Electric Propulsion Conference, Japan Society for Aeronautical and Space Sciences, Tokyo, 1984, pp. 79-86.

90. LaPointe, M., Rawlin, V., and Power, J., "High Power Electric Propulsion Technology at the NASA Lewis Research Center," Prepared for 6th Symposium on Space Nuclear Power Systems, Albuquerque, NM, Jan. 9-12, 1989.

91. Sovey, J.S., and Mantenieks, M.A., "Performance and Lifetime Assessment of MPD Arc Thruster Technology," AIAA-88-3211, July 1988 (NASA TM-101293).

92. Sovey, J.S., Mantenieks, M.A., Haag, T.W., Raitano, P., and Parkes, J.E., "Test Facility and Preliminary Performance of a $100 \mathrm{~kW} \mathrm{Class} \mathrm{MPD}$ Thruster," NASA TM-102021, 1989 (1989 JANNAF Propulsion Meeting).

93. Mantenieks, M.A., Sovey, J.S., Myers, R., Haag, T.W., Raitano, P., and Parkes, J.E., "Characterization of a 100-kW Class Applied-Field MPD Thruster," AIAA Paper 89-2710, July 1989.

94. Haag, T.W., "Design of a Thrust Stand for High Power Electric Propulsion Devices," Proposed for the 1989 JANNAF Propulsion Meeting, Cleveland, OH, May 1989.

95. Myers, R.M., "Plume Characteristics of MPD Thrusters: A Preliminary Examination," AIAA Paper 89-2832, July 1989.

96. LaPointe, M.R., "Numerical Simulation of Applied Field Steady State MPD Thrusters," proposed for the 1989 JANNAF Propulsion Meeting, Cleveland, $\mathrm{OH}$, May 1989.

97. Reed, C.B., and Sovey, J.S., "The Use of High Temperature Superconductors in Magnetoplasmadynamic Systems," NASA TM-101219, 1988.

98. Pollard, J.E., Lichtin, D.A., and Cohen, R.B., "RF Discharge Electrothermal Propulsion: Results for a Lab-Scale Thruster, "AIAA Paper $87-2124$, June 1987.

99. Whitehair, S., Asmussen, J., and Nakanshi, S., "Microwave Electrothermal Thruster Performance on Helium Gas," Journal of Propulsion and Power, Vol. 3, No. 2, Mar.-Apr. 1987, pp. 136-144.

100. Morin, T.J., and Hawley, M.C., "The Efficacy of Heating Low-Pressure $\mathrm{H}_{2}$ in a Microwave Discharge," Plasma Chemistry and Plasma Processing, Vol. 7, No. 2, June 1987, pp. 18ד-199. 
101. Hawley, M.C., Asmussen, J., Filpus, J.W. Frasch, L.L., Whitehair, S., Morin, T.J., and Chapman, R., "A Review of Research and Development on the Microwave-Plasma Electrothermal Rocket," AIAA Paper 87-1011, May 1987.

102. Frasch, L.L., Griffin, J.M., and Asmussen, J., "An Analys is of Electromagnetic Coupling and Eigenfrequencies for Microwave Electrothermal Thruster Discharges," AIAA Paper 87-1012, May 1987.

103. Filpus, J.W., and Hawley, M.C., "A Computer Model for the Recombination Zone of a Microwave-Plasma Electrothermal Rocket, "AIAA Paper 87-1014, May 1987.

104. Sercel, J., "Electron-Cyclotron-Resonance (ECR) Plasma Thruster Research," AIAA Paper 88-2916, July 1988.

105. Whitehair, S., and Asmussen, J., "The Experimental Performance of a Compact Microwave Electrothermal Thruster," Michigan State University, East Lansing, MI, 1988 (to be published).

106. Whitehair, S., Frasch, L.L., and Asmussen, J., "Experimental Performance of a Microwave Electrothermal Thruster with High Temperature Nozzle Materials," AIAA Paper 87-1016, 1987.

107. Zana, L.M., Kerslake, W.R., and Sturman, J.L., "Rail Accelerators for Space Transportation - An Experimental Investigation," NASA TP-2571, 1986.

108. Rice, E.E., Miller, L.A., and Earhart, R.W., "Preliminary Feasibility Assessment for Earth-to-Space Electromagnetic Railgun Launchers," NASA CR-167886, 1982.

109. Miller, L.A., Rice, E.E., Earhart, R.W., and Conlon, R.A., "Preliminary Analysis of Space Mission Applications for Electromagnetic Launchers," NASA CR-174748, 1984.

110. Kolm, H., "An Electromagnetic Slingshot for Space Propulsion," Technology Review, Vol. 79, June 1977, pp. 60-66.

111. O'Nei1, G.K., and O'Leary, B., eds., Space Based Manufacturing from Nonterrestrial Materials, Progress in Astronautics and Aeronautics, Vol. 57 , AIAA, New York, 1977.

112. Heppenheimer, T.A., "Achromatic Trajectories and Lunar Material Transport for Space Colonization." Journal of Spacecraft and Rockets, Vol. 15. No. 3, May-June 1978, pp. 176-183.

113. Billingham, J., Gilbreath, W.P., O'Leary, B., and Gosset, B., eds., Space Resources and Space Settlements, NASA SP-428, NASA, Washington, DC, 1979.

114. Hull, J.R., and Carney, L.M., "Application of Superconducting Technology to Earth-to-Orbit Electromagnetic Launch Systems," NASA TM-101134, 1988.

115. "Exploration Mission/Technology Planning Workshop." Workshop Proceedings, Vols. I \& II, Washington, DC, Nov. 14-17, 1988. 


\section{ORIGINAL PAGE \\ BLACK AND WHITE PHOTOGRAPH}

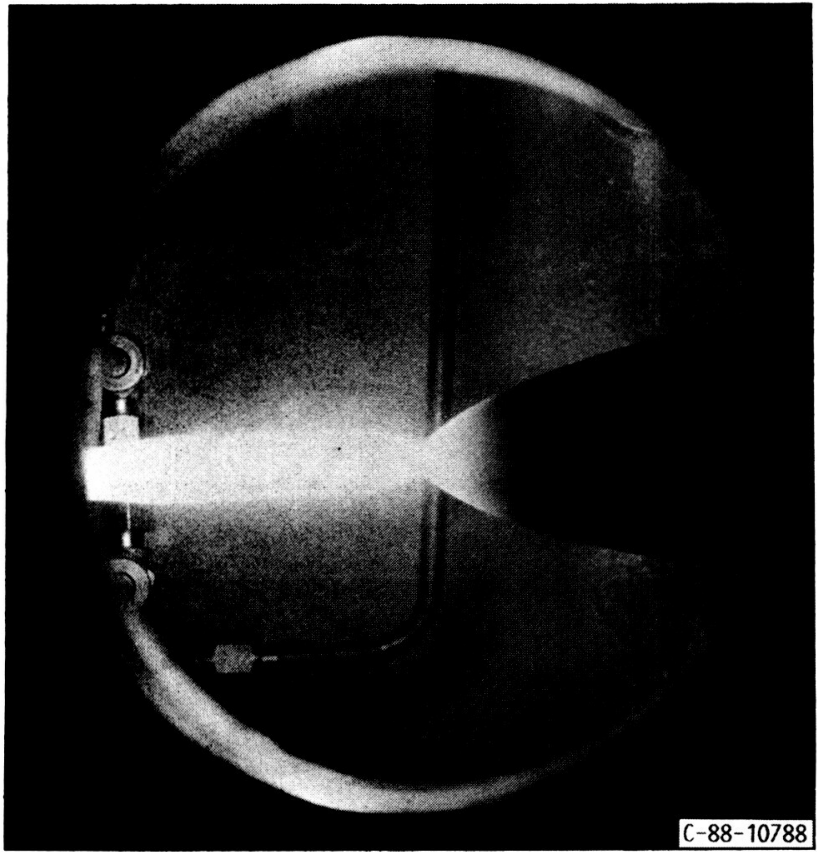

FIGURE 1. - ADVANCED 22-N Bi-PROPELLANT THRUSTER.

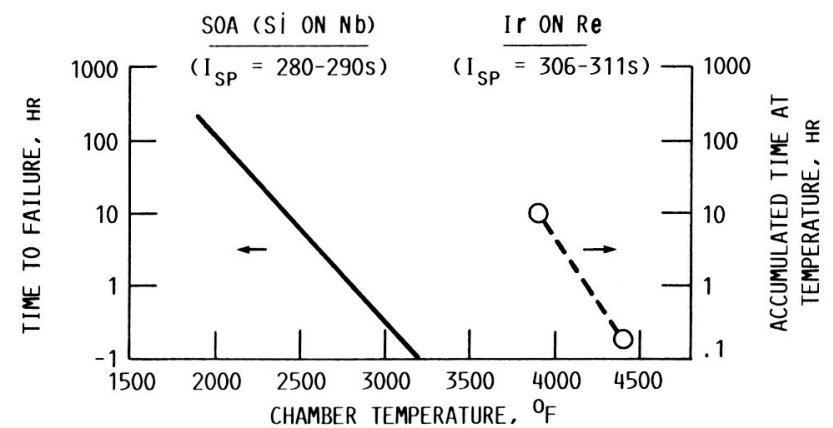

FIGURE 2. - PERFORMANCE AND LIFE EXTENSION PROVIDED BY IRIDIUM-COAIED RHENIUM THRUST CHAMBER.

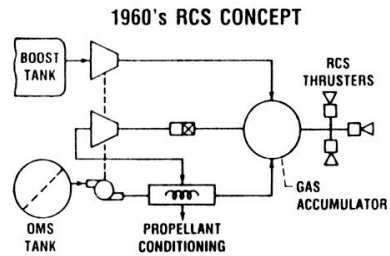

- $\mathrm{GH}_{2} / \mathrm{GO}_{2}$ RCS THRUSTERS

- pROPELLANT CONDITIONINg

$$
\begin{array}{|l|}
\hline \text { IMPACTS } \\
\text { - GREATEA (100 SEC) SYSTEM SPECIFIC IMPULSE } \\
\text { - ELMMNATEO COMPONEETS } \\
\text { - HEAT EXCHANGER/GASIFIER } \\
\text { - GASACCUMULATOR } \\
\text { - COMPRESSOR } \\
\text { - DECOUPLED THRUSTERIPROPELLANT MANAGEMENT }
\end{array}
$$

PROPOSED RCS CONCEPT

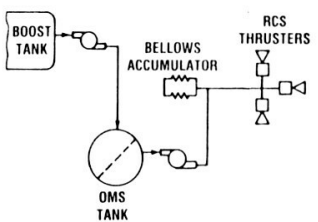

- $\mathrm{LH}_{2} / \mathrm{LO}_{2}$ RCS THRUSTERS

- NO PROPELLANT CONDITIONING

FIgURE 3. - INTEGRATED H/O AUXILIARY PROPULSION SYSTEM.

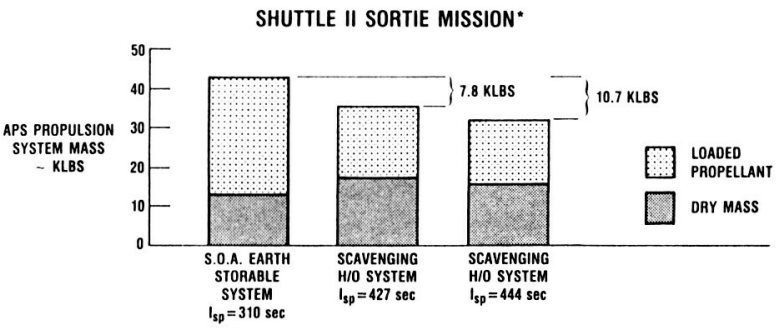

- A PAYLOAD BENEFIT OF 10,700 Ib PROJECTED FOR SHUTTLE II - MAY OFFER SIGNIFICANT OPERATIONAL BENEFITS

"VEHICLE MASS AND MISSION REQUIREMENTS SUPPLIED BY LaRC c0-88-37315

FIGURE 4. - PAYOFF OF INTEGRATED H/O PROPULSION. 
ORICINAL PAGE IS
OF POOR QUALITY

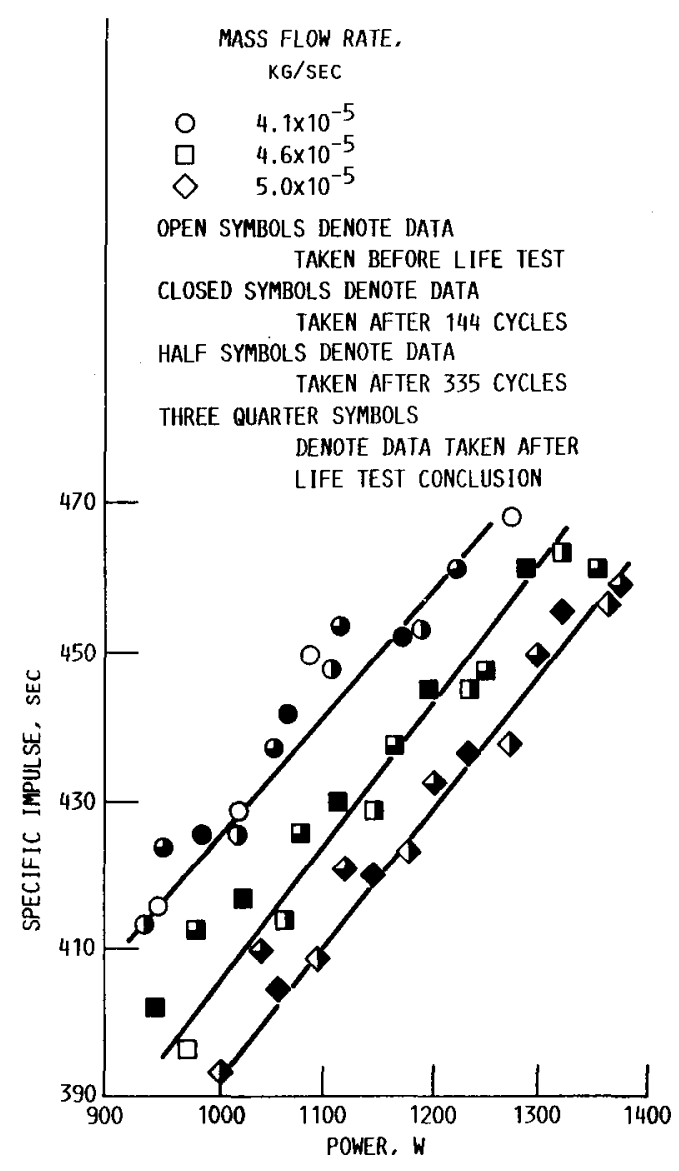

FIGURE 5. - LIFE-TEST 1-KW ARCJET SPECIFIC IMPULSE AS FUNCTION OF POWER.
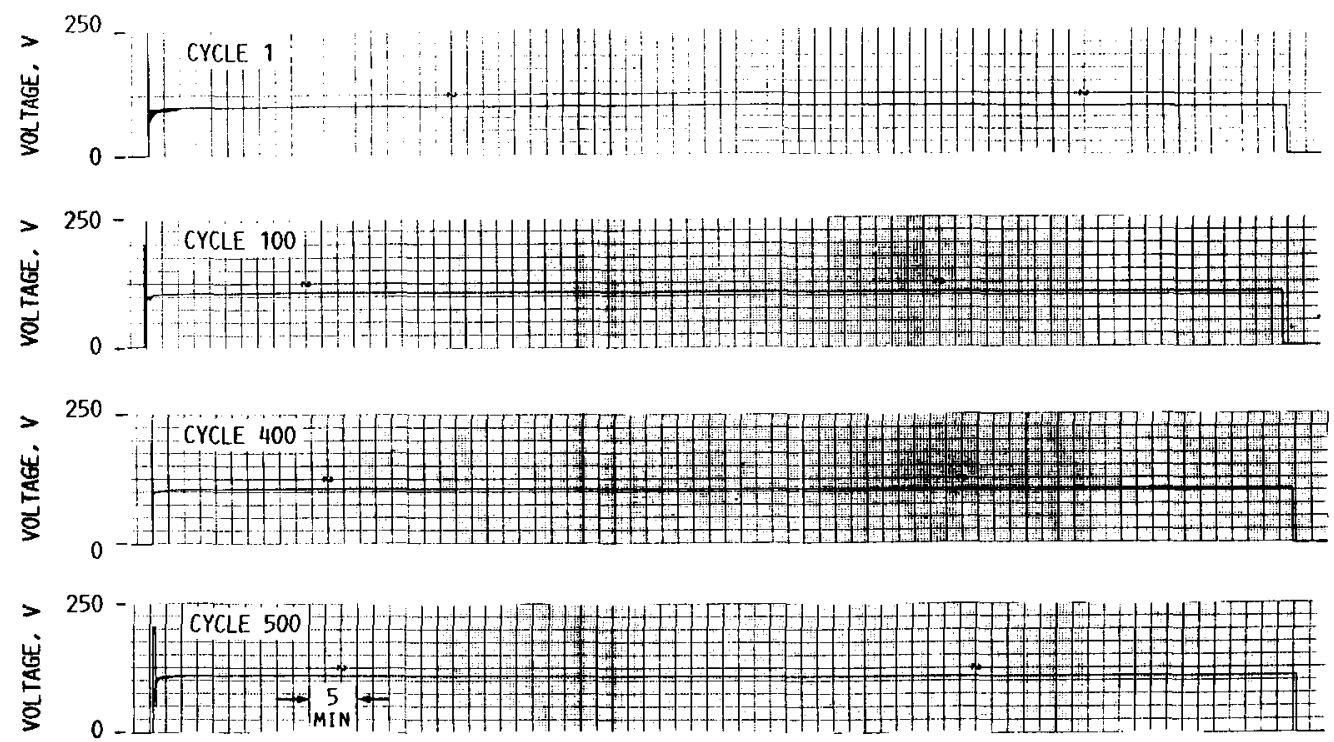

FIGURE 6. - LONG-TERM VOLTAGE TRENDS FOR LIFE-TEST 1-KW ARCJET. 
- ELECTRODE CONFIGURATION VERIFIED BY:

- PERformance oemonstrations

- LIFE TESTING

- PPU INTEgRation DEMONSTRATED

- tHeRMal INTERFACES Met

- DYNAMIC STRUCTURAL ANALYSIS COMPLETED

- COMMUNICATIONS IMPACTS ASSESSED

FIGURE 7. - FLIGHT-TYPE, KILOHATT-CLASS ARC.JET.
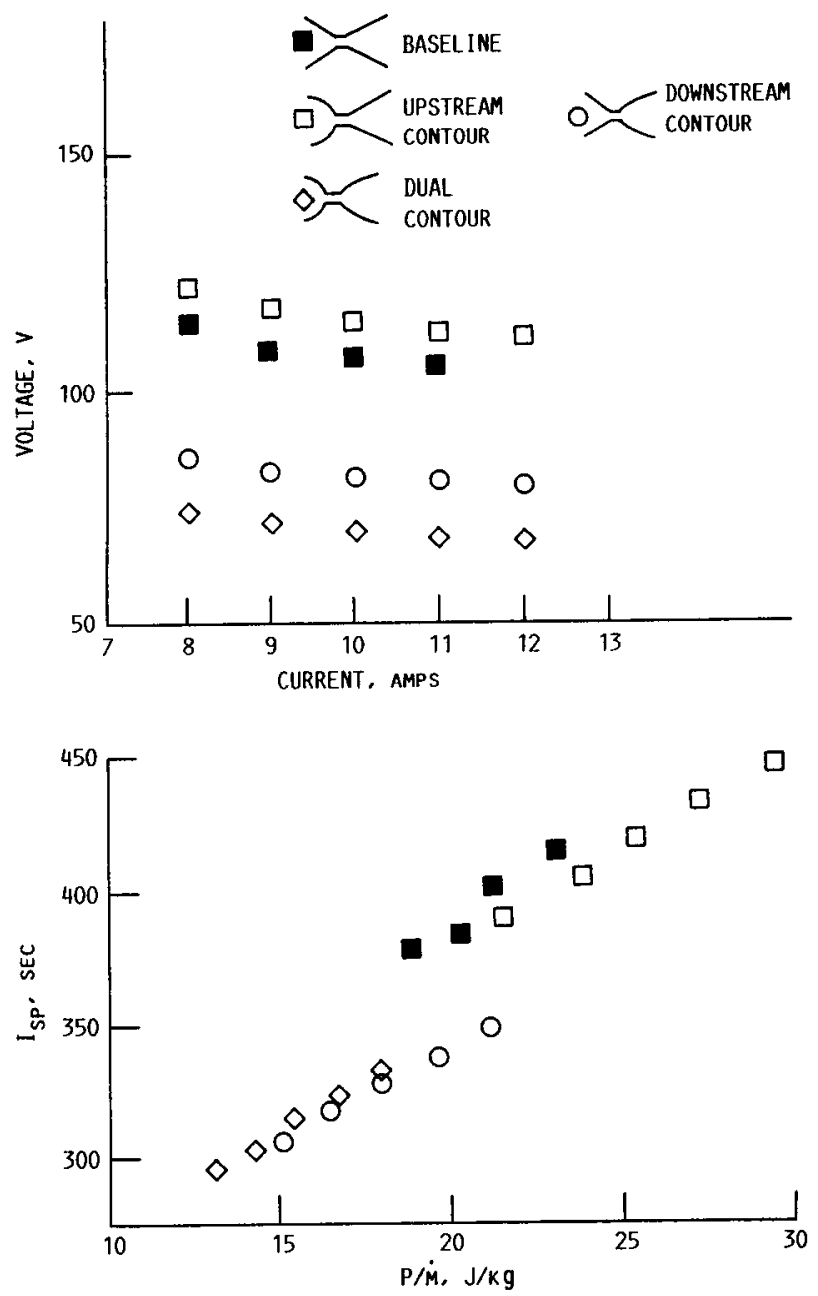

FIGURE 8. - NOZZLE GEOHETRY EFFECTS ON ARCJET CHARACTERISTICS. 


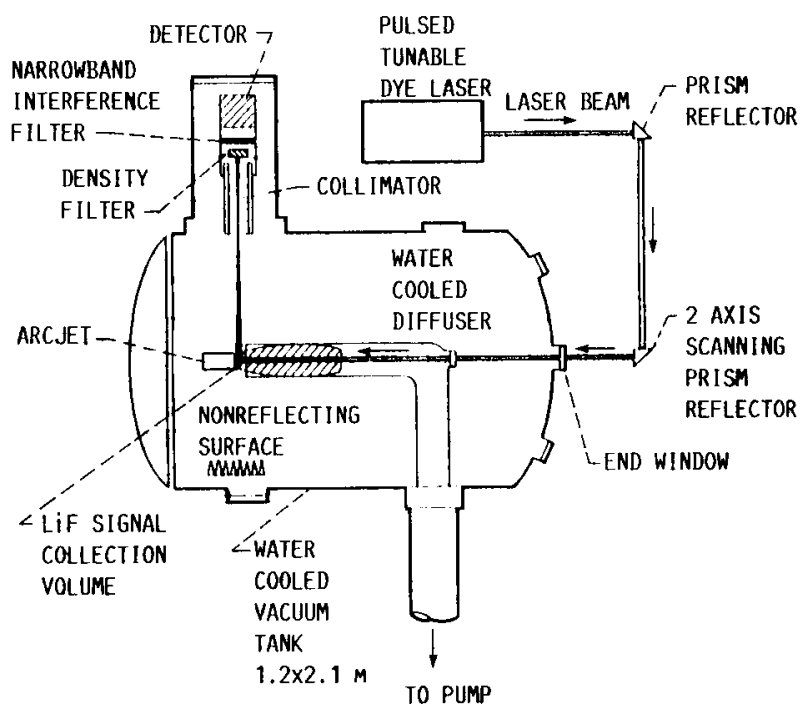

FIGURE 9. - JPL LASER INDUCED FLUORSCENCE (LiF) EXPERIMENTAL SETUP.

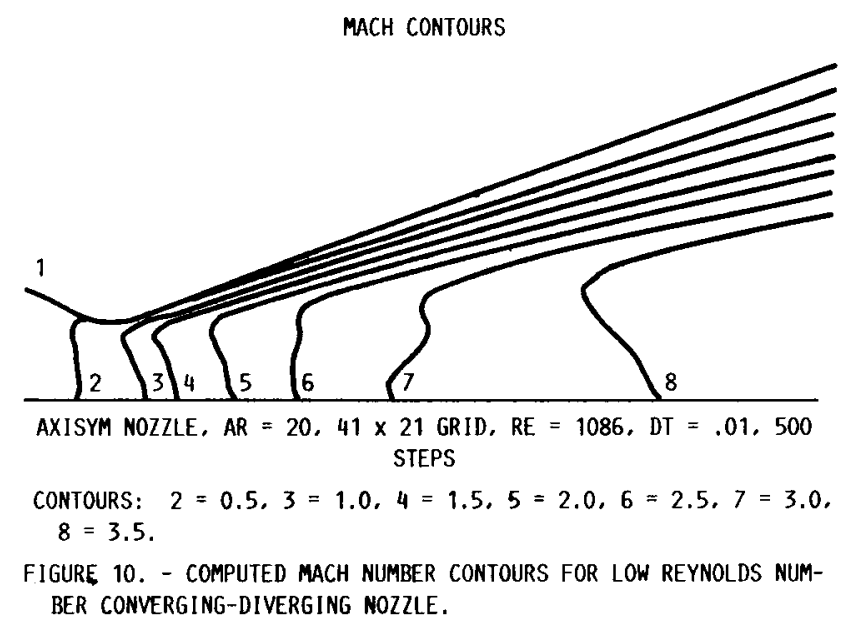

A INTERNAL THERMOCOUPLE LOCATIONS

* external thermocouple LOCATIONS

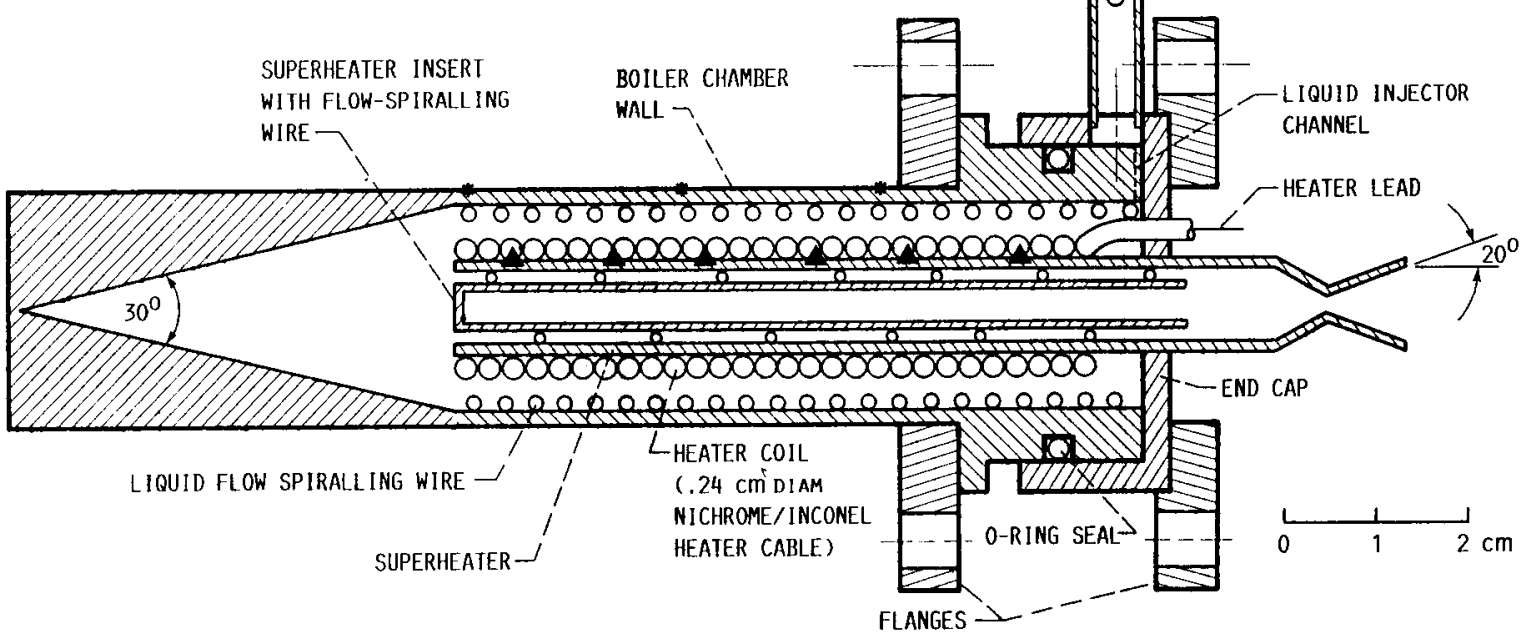

FIGURE 11. - INTEGRATED WATER VAPORIZER/RESISTOJET. 
- NEAR TERM PLANETARY/EARTH ORBIT MISSION TARGET $\approx 5$ TO 30 kW/THRUSTER, Xe - PATHFINDER CARGO MISSION TARGET $\approx 0.1$ TO 1 MW/THRUSTER, Ar OR Kr

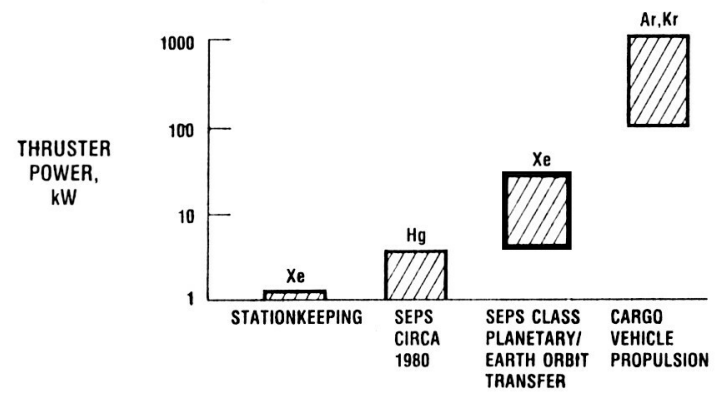

FIGURE 12. - ION ENGINE POWER RANGE FOR VARIOUS MISSIONS.

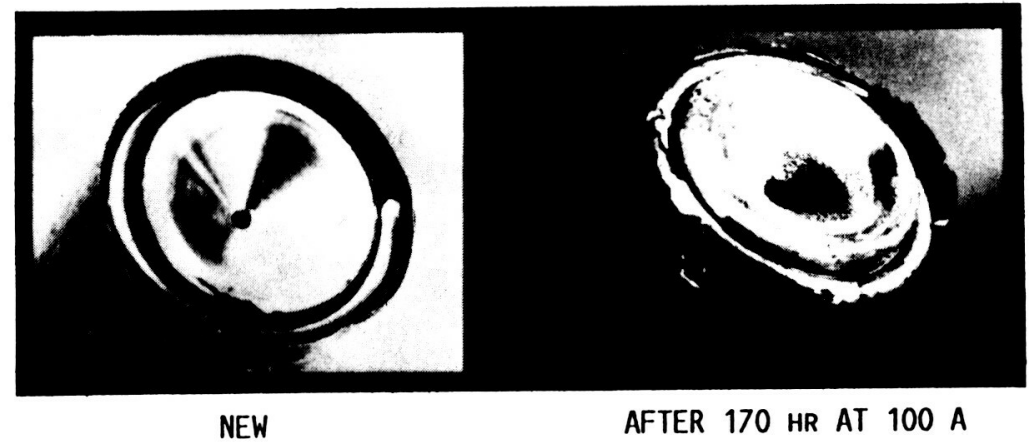

FIGURE 13. - JPL 1.27 CM DIAMETER HOLLOW CATHODE.

DIVERGENT FIELD

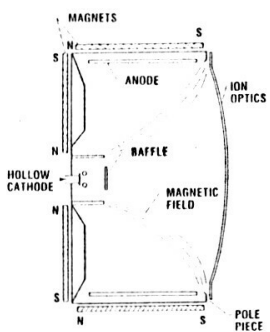

- VOLUME $\vec{B}$

- BAFFLE FOR DISCHARGE

IMPEDANCE CONTROL

- USED FOR SERT I, SERT II, IAPS, AND SEPS
RING CUSP

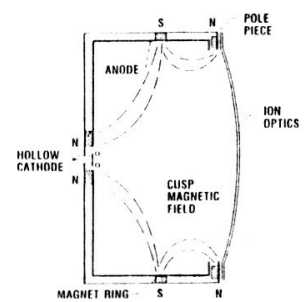

- BOUNDARY MAGNETIC FIELD

- NO BAFFLE

FIGURE 14. - DIVERGENT-FIELD AND RING-CUSP ION THRUSTERS. 


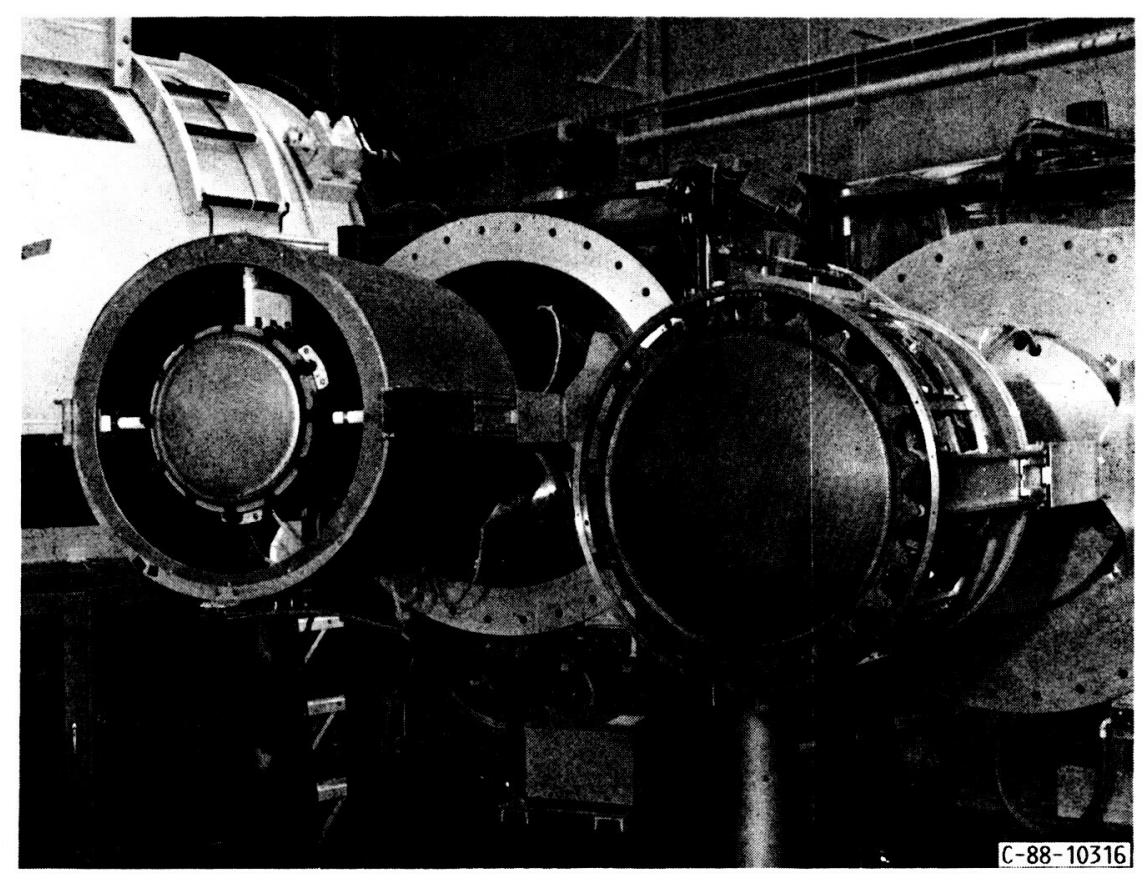

FIGURE 15. - $50 \mathrm{cM}$ ION THRUSTER.

LARGE AREA ION OPTICS PROVIDE:

- 2X INCREASE IN POWER OVER $30 \mathrm{~cm}$ DIA. THRUSTER

- EXTENDED SPECIFIC IMPULSE CAPABILITY

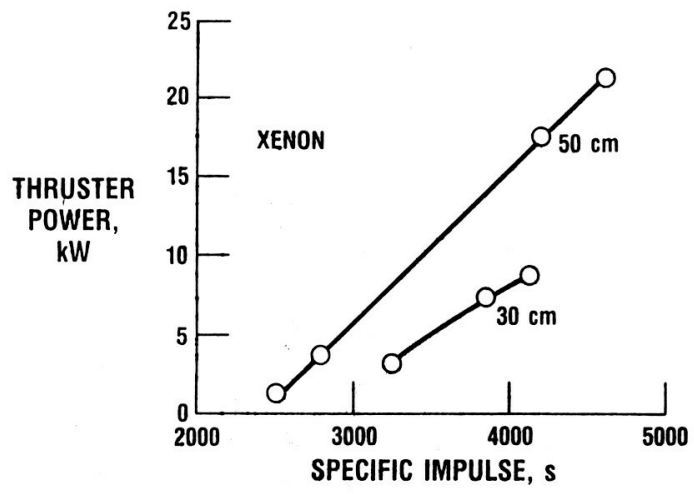

FIGURE 16. - ION EXTRACTION CAPABILITIES OF $30 \mathrm{cM}$ AND $50 \mathrm{cM}$ THRUSTERS.
- constant flow Strategy eliminates flow CONTROLLERS AND PERMITS OPERATION AT FIXED DISCHARGE CONDITIONS - MAY SIMPLIFY PPU

- ENGINE LIFE REQUIREMENT REDUCED 24\% BUT REQUIRES 9\% MORE PROPELLANT

$\begin{array}{cl}\text { THROTILING } & \bullet 3000 \mathrm{~kg} \text { PAYLOAD } \\ \text { STRATEGY } & \bullet \text { TITAN IV LAUNCH } \\ \text { CONSTANT FLOW } & -25 \mathrm{~kW} \text { ARRAY } \\ \text { VARIABLE FLOW } & -22 \mathrm{~kW} \text { XENON ION ENGINE }\end{array}$

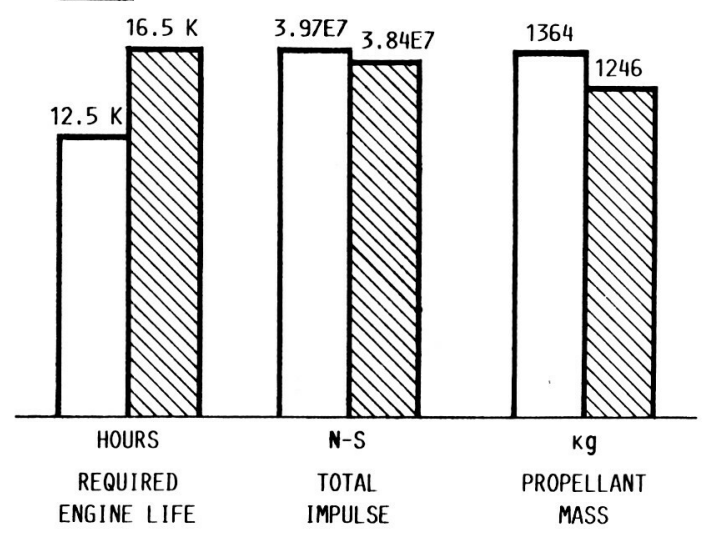

FIGURE 17. - ION ENGINE THROTTLING STRATEGY. 


\section{ORIGINAL PAGE \\ BLACK AND WHITE PHOTOCOARA}

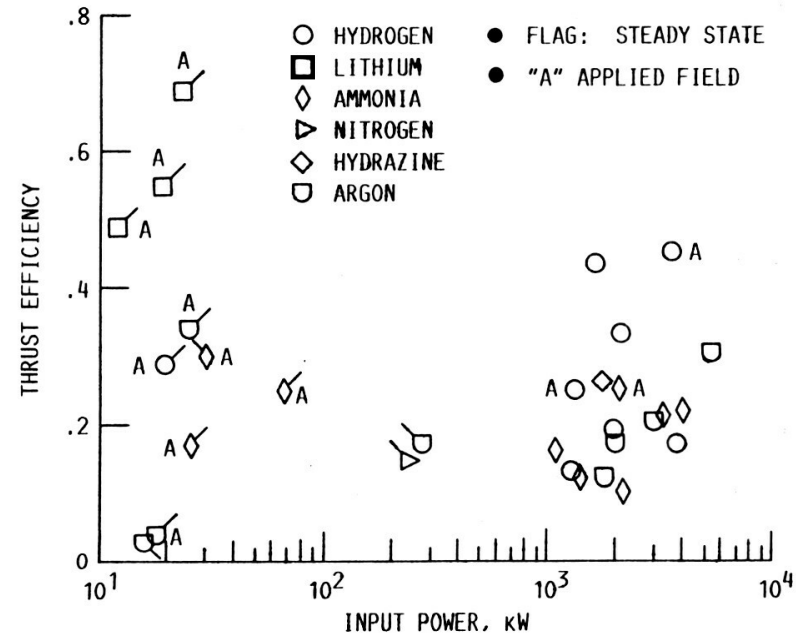

FIGURE 18. - DEMONSTRATED EFFICIENCY FOR MPD THRUSTERS.
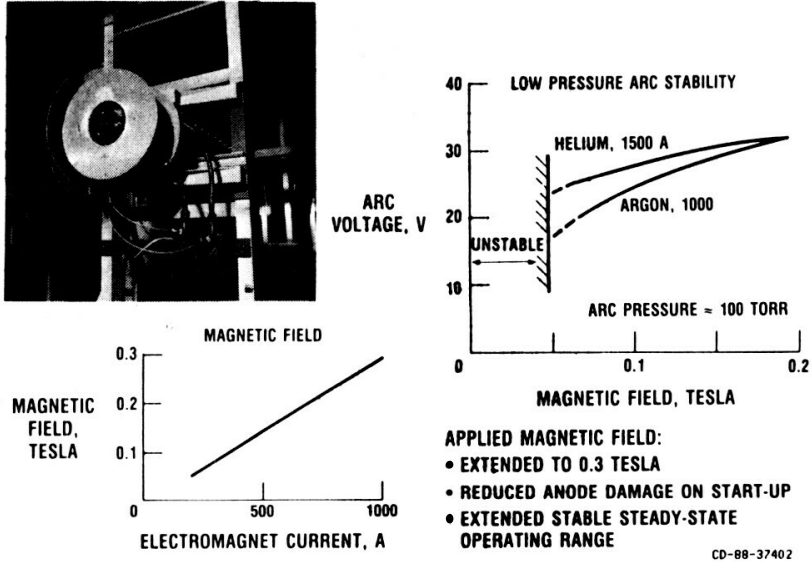

FIGURE 19. - OPERATING RANGE FOR LERC APPLIED-FIELD MPD THRUSTER.

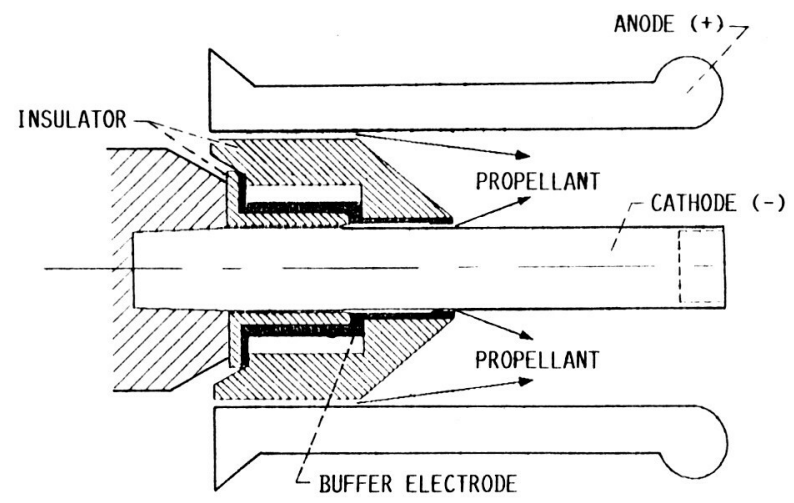

FIGURE 20. - JPL STEADY-STATE, SELF-FIELD MPD THRUSTER.
- DISTINCT STEADY-STATE OPERATING MODES OBSERVED BY D. KING IN 1987

- ONE MODE IS CHARACTERIZED BY A LUMINOUS CATHODE JET. A SECOND MODE HAS A COOLER CATHODE TIP AND NO CATHODE JET; THE TERMINAL VOLTAGE IS LOWER.

\section{- SECOND MODE MAY PROVIDE MORE EFFICIENT PLASMA ACCELERATION}
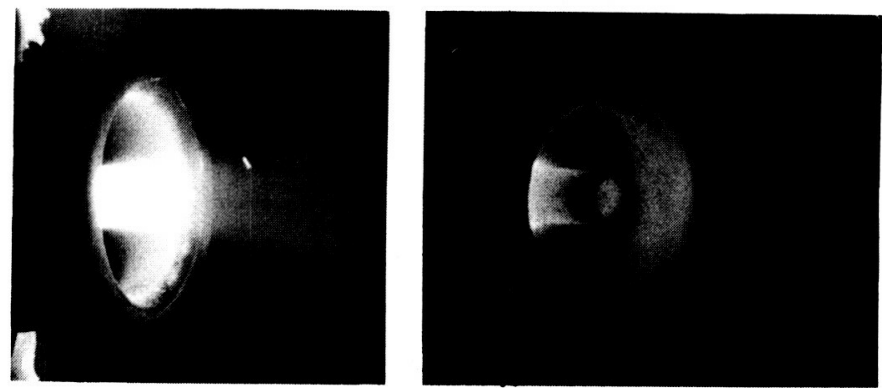

FIgURE 21. - STEADY-STATE, SELF-FIELD MPD MODE CHANGES. 


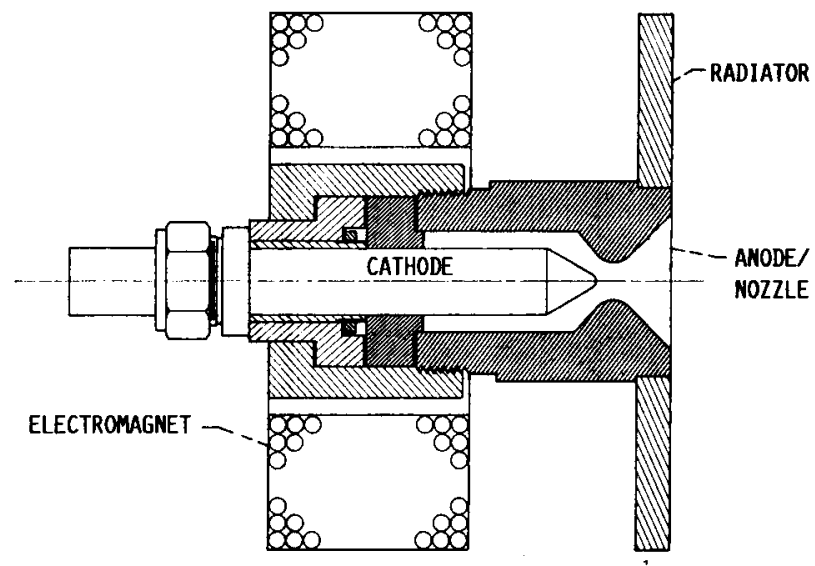

FIGURE 22. - JPL RADIATION-COOLED, APPLIED-FIELD MPD - THRUSTER DESIGN.

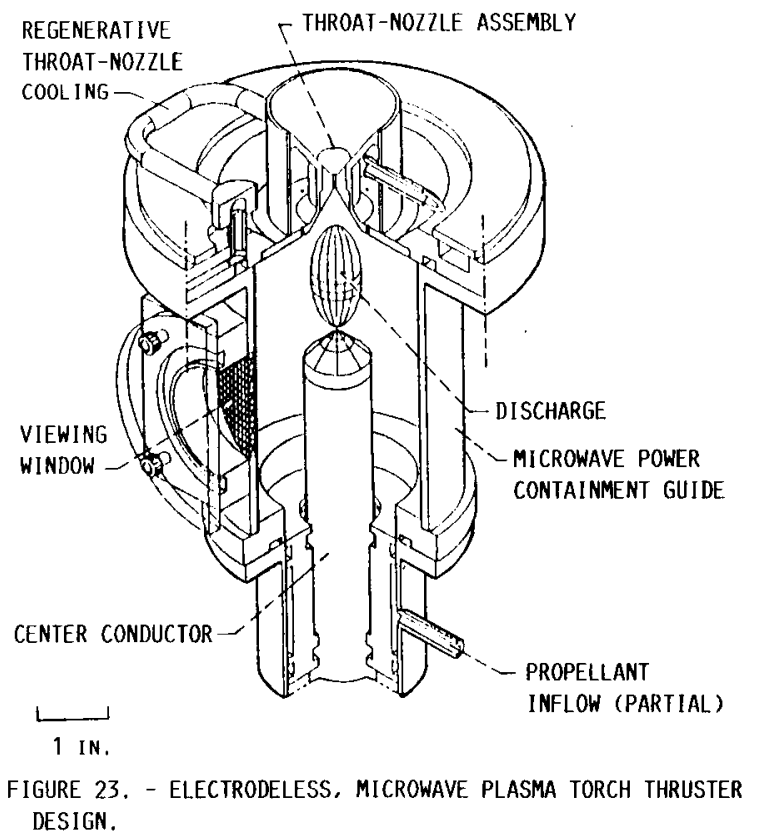




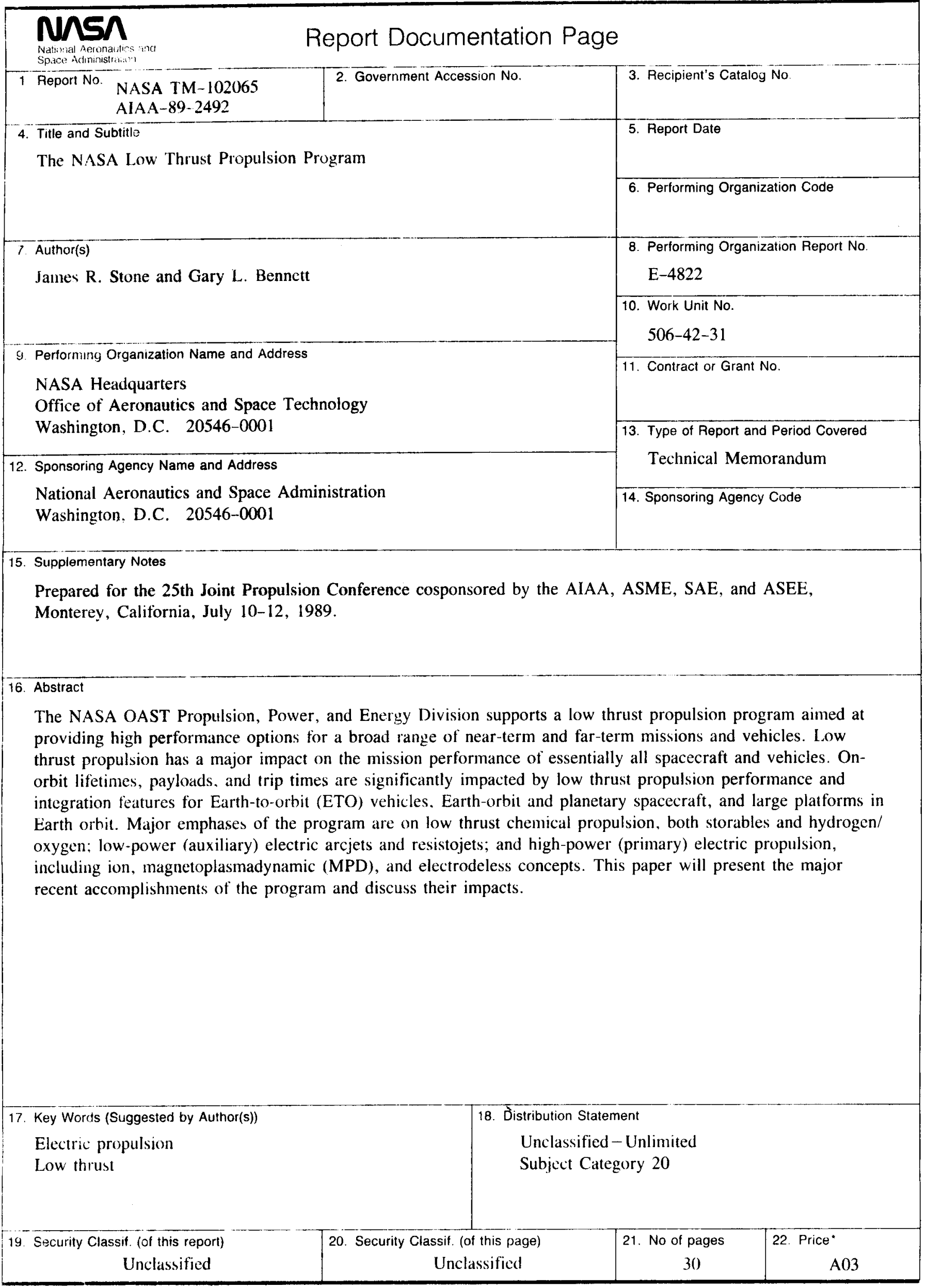

